\title{
Multivariate regression models in estimating the behavior of FRP tube encased recycled aggregate concrete
}

Ruoyu Jin ${ }^{\mathrm{a}, *}$, Libo Yan ${ }^{\mathrm{b}, \mathrm{,},}$, Alfred B.O. Soboyejo ${ }^{\mathrm{d}}$, Liang Huang ${ }^{\mathrm{e}}$, and Bohumil Kasal ${ }^{\mathrm{b}, \mathrm{c}}$ aschool of Environment and Technology, University of Brighton, UK.

${ }^{\text {b} C e n t r e ~ f o r ~ L i g h t ~ a n d ~ E n v i r o n m e n t a l l y-F r i e n d l y ~ S t r u c t u r e s, ~ F r a u n h o f e r ~ W i l h e l m-K l a u d i t z-I n s t i t u t W K I, ~}$ BienroderWeg54E, Braunschweig, Germany

'Department of Organic and Wood-Based Construction Materials, Technical University of Braunschweig, Hopfengarten 20, Braunschweig, Germany

${ }^{\mathrm{d}}$ Department of Food, Agricultural, and Biological Engineering, Department of Aerospace Engineering, and John Glenn Institute for Public Policy and Public Service, The Ohio State University, Columbus, Ohio, USA.

${ }^{\text {e}}$ College of Civil Engineering, Hunan University, Changsha 410082, China

*Corresponding authors: R.Jin@brighton.ac.uk;l.yan@tu-braunschweig.de

\begin{abstract}
This study applied newly developed multivariate statistical models to estimating the mechanical properties of recycled aggregate concrete cylinder encased by fiber reinforced polymer (FRP). Two different types of RFPs were applied, namely flax FRP and polyester FRP. Ten independent variables were predefined including the FRP type and cylinder size. It was found that several mixed models outperformed the traditional linear regression approach, based on the accuracy and residual value distribution. Individual factor analysis indicated that the fiber thickness and layer number had more significant impacts on the strength and strain of FRP-encased concrete's transitional point, compared to their impacts at the ultimate state.
\end{abstract}

\section{Keywords}

Recycled aggregate concrete (RAC); fiber reinforced polymer (FRP); size effect; slenderness; mechanical properties; statistical modeling; multivariate regression analysis; mixed model

\section{Introduction}


Concrete is the most widely consumed construction material world[1]. It accounts for $50 \%$ to $70 \%$ of total construction and demolition (C\&D) wastes[2]. Crushed bricks are another widely seen C\&D wastes in developing countries including China, where the overwhelming C\&D wastes generated are in an urgent need of diversion as indicated by Jin et al [3]. Recycling and reusing old concrete and bricks from C\&D wastes in recycled aggregate concrete (RAC) production has been widely studied[3]. The replacement percentage of recycled aggregate (RA) to virgin aggregate in concrete mix design varied among studies, from below 30\% [4] to 100\%[5]. Adding more recycled contents could cause negative effects in concrete properties such as strength, and durability [6]. Therefore, optimizing the sustainability and quality of concrete is an issue as industry practitioners are concerned on the inferior quality of recycled products [7]. There have been different ways that have been studied to make up the inferior quality of concrete by using recycled contents, such as adding proper supplementary cementitious materials in mix design [8], and selecting the proper source of RA [9].

Confining concrete specimens has been found effective to improve the mechanical properties according to multiple studies [10, 11]. More recently, the research of fiber reinforced polymer (FRP)-confined concrete specimens have been extended from conventional concrete [12] to RAC, such as carbon FRP and glass FRP $[13,14]$. The problem of applying carbon FRP and glass FRP in civil engineering is their higher cost and not being environmentally friendly [15]. Alternative types of FRPs have been tried to reduce the cost and environmental impacts of carbon FRP and glass FRP, such as the plant-based natural flax FRP (FFRP) [16], and the polyester FRP (PFRP)[15]. In recent years, researchers [15, 17] have applied FFRP and PFRP to encase concrete specimens containing RAs. Mechanical properties of 
FRP-encased RAC specimens were tested [15, 17], including the stress and strain at transitional points and ultimate failure state.

Statistical analyses were applied by Huang et al. [15]to study the correlational relationship between the aforementioned mechanical properties (i.e., stress or strain) and individual independent variables (IVs) such as specimen size, slenderness ratio, and confinement condition of FRP, etc. The limitation of the single factor variance analysis was that it could not evaluate or measure the effects of multiple IVs. There is also a lack of quantitative and comprehensive measurement of these multiple IVs' impacts on the mechanical properties of FRP-confined RAC specimens. Various analytical and modeling methods have been applied in predicting concrete properties, such as regression analysis[18], neural network[19], fuzzy logic[20], computer programming[21], and other data mining algorithms [22, 23]. These multiple data analytical methods have been widely used to predict concrete mechanical properties, including compressive strength [24, 25], structural capacity [26, 27], as well as structural or shrinkage behaviour $[28,29]$. These methods adopted various IVs in predicting the target RRVs, such as the mix design involving environmentally friendly or "green" concrete materials [30, 31].

A problem with applying these data analytical methods in predicting concrete performance was that there has been insufficient inclusion of a comprehensive list of multiple IVs [32]. There have not been enough studies focusing on measuring the individual effect of each IV in the RRV targeting on concrete performance. The application of data analytical approach in evaluating the performance of FRP-confined concrete is limited to single linear approach[17]. Multiple potential IVs that influence RRVs within FRP-confined concrete specimens need to be studied simultaneously to explore the relative significance of these IVs, such as specimen size, 
slenderness ratio, engineering properties of RFP sheets, and the originally unconfined concrete properties identified from multiple previous studies [15, 33]. As the research of applying FRPs in improving concrete performance, including adopting different types of FRPs (e.g., PFRP and FFRP) in RAC, is gaining more attention according to existing studies $[34,35]$, there is a rising need to apply a proper data analytical method incorporating these multiple IVs in predicting properties of concrete confined by different FRPs.

Applying statistical or mathematical models in the research of cement-based composites is not considered new [32]. Multiple IVs involving concrete mix design (water-to-cement ratio) were adopted by multiple studies [36, 37]. These studies used single IV or linear regression approach. The traditional simple regression methods are likely to generate biased statistical results [38]. The other limitation is the accuracy of predication measured by determination coefficient (i.e., $R^{2}$ value). A review of existing studies [37, 39] adopting regression models in estimating concrete mechanical properties showed relatively lower accuracy with $R^{2}$ value below 0.700 or even 0.600 . Although the desired $R^{2}$ value depends on the decision-making context or research objectives and it could vary from $10 \%$ to $99 \%[40]$, a fairly high $R^{2}$ value is expected in the predictionof concrete properties. For example, it is not uncommon to see $R^{2}$ value higher than 0.9000 according to the study of Omran et al. [24].So far these non-linear or mixed statistical methods have not been widely applied in evaluating concrete properties, especially in FRP-confined RAC specimens to improve the predication accuracy. Researchers believe that these statistical methods could further quantify the effects of multiple IVs in FRP-confined concrete properties.

This study aims to introduce the multivariate regression analysis as the alternative approach to establishing the correlational relationship between the mechanical 
properties of FFRP and PFRP-encased concrete specimens and a comprehensive list of IVs. Concrete specimens adopted in this research contain aggregates from recycled concrete and clay brisk wastes (i.e., RAC-RCBA). Totally ten independent variables (e.g., tensile strength of PFRP sheets) are adopted in the multivariate regression model to predicting four major response random variables (RRVs), including strength and strain at transitional and ultimate points. Multiple multivariate regression models are proposed and tested of their accuracy, including non-linear and mixed models initiated by Jin et al. [32]. This study contributes to the existing scholarly work of FRP-confined RAC in that: 1) proposing and testing multiple non-linear and mixed regression models as alternative methods to the traditional linear or single-factor approach in estimating the mechanical properties of FRP-confined RAC; 2) adopting a comprehensive list of IVs (e.g., size, FRP properties) in these regression models and testing their effects; 3) comparing these multiple models in their accuracy and identifying the best-fit model; and 4) investigating individual IVs' effects in RRVs.

The rest of this study consists of these following sections: 1) Section 2 describes the materials and experimental procedure in obtaining the data needed for multivariate regression analysis; 2) Section 3 demonstrates and discusses the accuracies of various multivariate regression models; and 3) Section 4concludes the study.

\section{Methods and Materials}

\subsection{Materials}

Recycled concrete and clay brick wastes (i.e., RAC-RCBA)were used as the recycled coarse aggregate in this study. They were collected from Jinke Resource Recycling Co. located in Henan Province China. They consisted of around 60\% of clay brick aggregates and $40 \%$ of recycled concrete and mortar aggregates by mass 
content. Both recycled and natural coarse aggregates in this research had the particle size ranging from $5 \mathrm{~mm}$ to $15 \mathrm{~mm}$. Fig. 1 provides the image of recycled aggregates mixed with clay bricks, old concrete, and mortar.

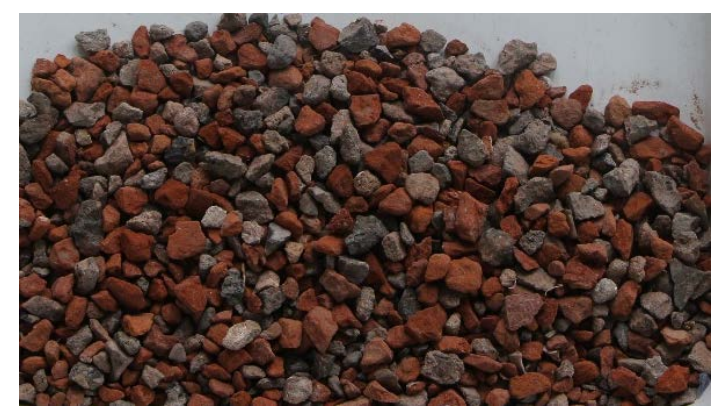

Fig.1. Recycled aggregates used in the research of RAC-RCBA

Tests were conducted to investigate the aggregates' properties which are presented in Table 1.

Table 1.

Properties of aggregates

\begin{tabular}{ccccc}
\hline Aggregate & Source & $\begin{array}{c}\text { Apparent } \\
\text { density } \\
\left(\mathbf{g} / \mathbf{c m}^{3}\right)\end{array}$ & $\begin{array}{c}\text { Particle size } \\
\mathbf{( m m})\end{array}$ & $\begin{array}{c}\text { Water } \\
\text { absorption } \\
\text { rate }\end{array}$ \\
\hline $\begin{array}{c}\text { Virgin coarse } \\
\text { aggregate }\end{array}$ & macadam & 2.52 & $5-15$ & $0.91 \%$ \\
RAC-RCBA & $\begin{array}{c}\text { 60\% of clay brick aggregates, } \\
\text { 40\% of recycled concrete and } \\
\text { mortar aggregates }\end{array}$ & 2.36 & $5-15$ & $8.09 \%$ \\
$\begin{array}{c}\text { Natural fine } \\
\text { aggregate }\end{array}$ & river sand & 1.58 & $0.35-0.5$ & $5.59 \%$ \\
\hline
\end{tabular}

Ordinary Portland cement with strength of $42.5 \mathrm{MPa}$ was used for the concrete mixture. Concrete specimens were cured in the room temperature of $(20 \pm 3)^{\circ} \mathrm{C}$ under the humidity of 95\% for 28 days. Fig.2 displays these two types of polyester fiber reinforced polymers (RFPs) tubes that were used to encase concrete specimens. 


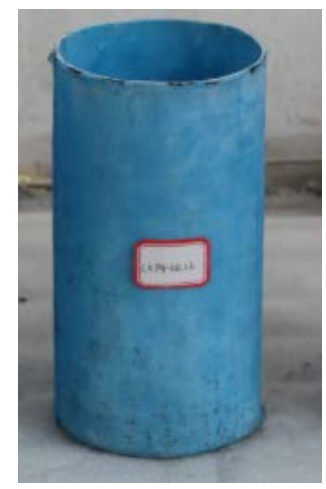

Polyester FRP (PFRP)tube

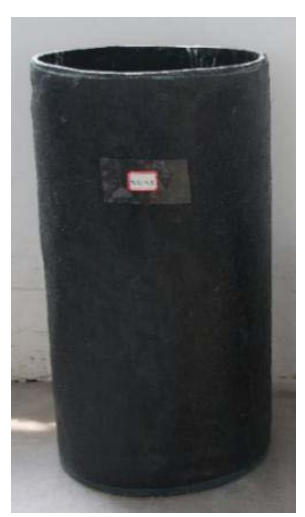

Flax FRP (FFRP) tubes

Fig.2. Examples of PFRP and FFRP tubes.

These tubes showcased in Fig.2 had different sizes. The mechanical properties of these two types of FRPs were determined following ASTM D3039-M08[41]. FRPs were measured of their tensile strength, strain and elastic modulus using flat coupon tests. Configurations of these flat coupons can be found in Huang et al. [15] and Yan et al. [17]. Table 2lists the results of coupon tests.

\section{Table 2.}

Average results of flat coupon tests to PFRP and FFRP

\begin{tabular}{ccccccc}
\hline $\begin{array}{c}\text { Type of } \\
\text { FRP }\end{array}$ & $\begin{array}{c}\text { Number of FRP } \\
\text { layers }\end{array}$ & $\begin{array}{c}\text { Number of } \\
\text { specimens }\end{array}$ & $\begin{array}{c}\text { Thickness } \\
(\mathrm{mm})\end{array}$ & $\begin{array}{c}\text { Tensile } \\
\text { stress (MPa) }\end{array}$ & $\begin{array}{c}\text { Tensile } \\
\text { strain (\%) }\end{array}$ & $\begin{array}{c}\text { Elastic modulus } \\
(\mathrm{GPa})\end{array}$ \\
\hline FFRP & 3 & 5 & 1.85 & 85.1 & 2.59 & 3.68 \\
& 6 & 5 & 3.69 & 81.3 & 2.94 & 3.22 \\
& 9 & 5 & 5.54 & 69.3 & 3.16 & 2.66 \\
\hline PFRP & 2 & 6 & 1.72 & 31.52 & 8.50 & 0.89 \\
& 4 & 6 & 2.89 & 37.51 & 11.61 & 0.92 \\
& 6 & 6 & 4.25 & 40.81 & 14.87 & 0.96 \\
& 8 & 6 & 5.12 & 43.48 & 16.04 & 0.99 \\
\hline
\end{tabular}

It can be found from Table 2 that PFRP has lower tensile strength but significantly higher tensile strain compared to FFRP.

\subsection{Concrete mix design}


In this study, RRVs(i.e., response random variables) and IVs (i.e., independent variables) come from totally 102 axial compression test samples which consistedof PFRP-confined concrete containing aggregates from RAC-RCBA, as well as FFRP-confined concrete specimens with RAC-RCBA.A total of 66 cylindrical specimens of PFRP-confined RAC-RCBA and 36 specimens of FFRP-confined RAC-RCBA were adopted for the data analysis. The mix design parameters (e.g., water-to-cement ratios and replacement ratios of RAC-RCBA to natural aggregates) were designed and the 7-day standard cube compressive strength of RAC-CBA specimens was performed by Huang et al. [15] and Yan et al. [17]in the trial tests. The trial tests indicated that a 70\% replacement rate of RAC-RCBA with other mix design parameters shown in Table 3could achieve the optimized 7-day compressive strength. As seen in Table 3, four different types of mix design of concrete specimens were applied to prepare the concrete specimens.

Table 3.

Mix design of concrete specimens for FRP-confined RAC-RCBA

\begin{tabular}{|c|c|c|c|c|c|c|c|}
\hline \multirow{2}{*}{$\begin{array}{c}\text { Type of } \\
\text { RAC-RCBA }\end{array}$} & \multirow{2}{*}{$\begin{array}{l}\text { Water } \\
\left(\mathrm{kg} / \mathrm{m}^{3}\right)\end{array}$} & \multirow{2}{*}{$\begin{array}{l}\text { Portland } \\
\text { Cement } \\
\left(\mathrm{kg} / \mathrm{m}^{3}\right)\end{array}$} & \multirow{2}{*}{$\begin{array}{l}\text { Naturalfine } \\
\text { aggregate } \\
\left(\mathrm{kg} / \mathrm{m}^{3}\right)\end{array}$} & \multirow{2}{*}{$\begin{array}{l}\text { Naturalc } \\
\text { oarse } \\
\text { aggregate } \\
\left(\mathrm{kg} / \mathrm{m}^{3}\right)\end{array}$} & \multicolumn{2}{|c|}{ Recycled coarse aggregate $\left(\mathrm{kg} / \mathrm{m}^{3}\right)$} & \multirow{2}{*}{$\begin{array}{l}\text { Replacement } \\
\text { ratio of } \\
\text { recycled coarse } \\
\text { aggregate }\end{array}$} \\
\hline & & & & & $\begin{array}{c}\text { Recycled clay } \\
\text { brick aggregate } \\
(60 \%)\end{array}$ & $\begin{array}{c}\text { Recycled concrete } \\
\text { and mortar } \\
\text { aggregate }(40 \%)\end{array}$ & \\
\hline FFRP-C2 & 297.5 & 538.3 & 520.2 & 312.4 & & 729.0 & $70 \%$ \\
\hline FFFP-C3 & 237.5 & 600.9 & 520.2 & 312.4 & & 729.0 & $70 \%$ \\
\hline PFRP-C2 & 329.11 & 470.22 & 600.22 & 360.13 & & 600.22 & $70 \%$ \\
\hline PFRP-C3 & 329.11 & 658.22 & 537.56 & 322.53 & & 537.56 & $70 \%$ \\
\hline
\end{tabular}

C2 and C3 in Table 3indicate the design strength of unconfined concrete specimens at Day 28. C2 refer to the compressive strength between $20 \mathrm{MPa}$ and 30 $\mathrm{MPa}$, and C3 means the strength between $30 \mathrm{MPa}$ and $40 \mathrm{MPa}$. Ordinary Portland cement with the strength of $42.5 \mathrm{MPa}$ was used in the mix design.

\subsection{Test method}


All specimens, including unconfined ones and those encased by PFRP or FFRP, were tested of their mechanical properties under monotonic axial compression. A servo-hydraulic compression test machine (MTS SANS YAW6506, hydraulic, Shenzhen) following ASTM C39[42] was used in this study. Specimens were loaded by a displacement-control model until they failed. The displacement rate was proportional to the cylinder height (i.e., $0.07 \mathrm{~mm} / \mathrm{min}, 0.13 \mathrm{~mm} / \mathrm{min}, 0.2 \mathrm{~mm} / \mathrm{min}$, $0.27 \mathrm{~mm} / \mathrm{min}, 0.3 \mathrm{~mm} / \mathrm{min}$, and $0.4 \mathrm{~mm} / \mathrm{min}$ for cylinders with the height of $100 \mathrm{~mm}$, $200 \mathrm{~mm}, 300 \mathrm{~mm}, 400 \mathrm{~mm}, 450 \mathrm{~mm}$, and $600 \mathrm{~mm}$ respectively). As described in Huang et al. [15] and Yan et al. [17], four axial strain gauges and four loop strain gauges were installed symmetrically on the surface at the middle-height of specimens to monitor the axial strain and loop strainrespectively. Another four axial strain gauges were installed on the surface at two ends of specimens to monitor the axial strain of FRP tubes. The axial displacement was measured by built-in linear variable displacement transducers of the compressive test machine. The axial displacement and strain, lateral strain, and applied load were recorded simultaneously during the test.

\subsection{Defining IVs in estimating the behavior of FRP tube-confined RCA-RCBA}

Following the tests illustrated by Yan et al. [17], the data of mechanical properties (i.e., RRVs) of concrete specimens and potential IVs that could affect RRVs are defined in Table 4. These IVs were defined through a comprehensive summary from previous studies, for example, the size of FRP tube measured by cylinder diameter and the slenderness ratio [15].

\section{Table 4.}

Definitions of RRVs and IVs in the multivariate regression analysis

\begin{tabular}{lll}
\hline Variables & Symbol & Definition \\
\hline $\mathrm{Y}_{1}$ & $\mathrm{f}_{\mathrm{ct}}(\mathrm{MPa})$ & Strength at the transitional point for RCA-RCBA specimens \\
$\mathrm{Y}_{2}$ & $\varepsilon_{\mathrm{ct}}$ & Strain at the transitional point
\end{tabular}




\begin{tabular}{lll}
$\mathrm{Y}_{3}$ & $\mathrm{f}_{\mathrm{cu}}(\mathrm{MPa})$ & Strength at the transitional point for RCA-RCBA specimens \\
$\mathrm{Y}_{4}$ & $\varepsilon_{\mathrm{cu}}$ & Strain at the transitional point \\
$\mathrm{X}_{1}$ & $\rho_{f r p}$ & Fiber volume content of the specimens \\
$\mathrm{X}_{2}$ & $t_{f r p}(\mathrm{~mm})$ & Thickness of the FRP tube \\
$\mathrm{X}_{3}$ & $\mathrm{n}_{f r p}$ & Number of layers in FRP tubes \\
$\mathrm{X}_{4}$ & $\mathrm{f}_{f r p}(\mathrm{MPa})$ & Tensile strength of FRP sheets \\
$\mathrm{X}_{5}$ & $\varepsilon_{f r p}$ & Tensile strain of FRP sheets \\
$\mathrm{X}_{6}$ & $\mathrm{E}_{f r p}$ & Elastic modulus of FRP sheets \\
$\mathrm{X}_{7}$ & $f_{c o}(\mathrm{Mpa})$ & Compressive strength of the unconfined RAC-RCBA cylinder \\
$\mathrm{X}_{8}$ & $\mathrm{E}_{\mathrm{c}}$ & Elastic modulus of the cylinders \\
$\mathrm{X}_{9}$ & $\mathrm{~d}$ & Cylinder diameter \\
$\mathrm{X}_{10}$ & $\mathrm{~h} / \mathrm{d}$ & Ratio of cylinder height to diameter representing the slenderness \\
\hline
\end{tabular}

These four different RRVs were defined according to the axial stress-strain monitoring during the axial tests. Fig.3 illustrates the stress-strain developments for both unconfined and FRP-confined specimens.

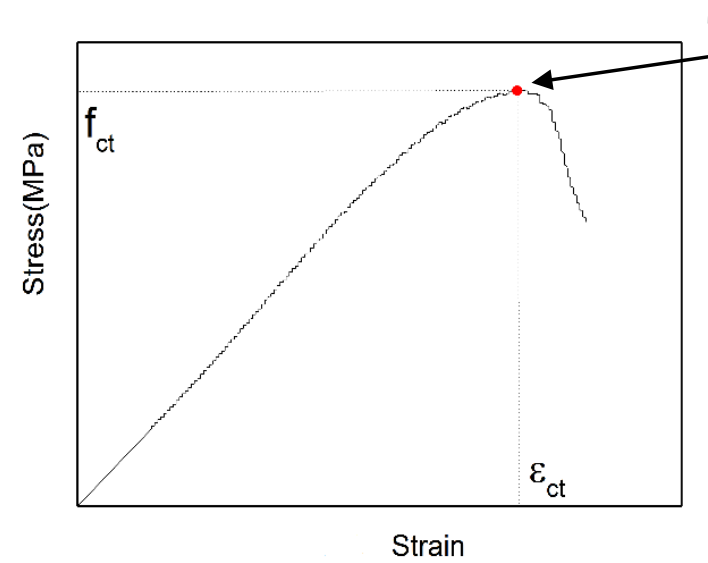

a) Axial stress-strain curves for unconfined concrete cylinders

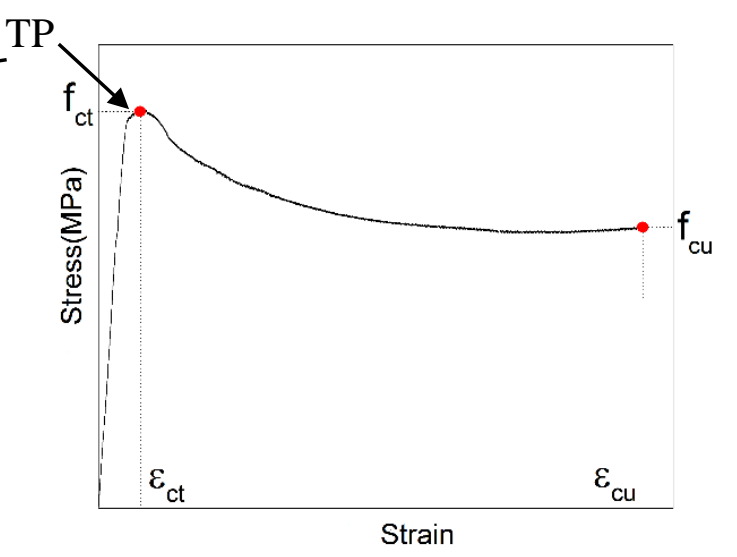

b) Axial stress-strain curves for confined concrete cylinders

Fig.3. Definition of axial stress and strain at transitional and ultimate states (adapted from Huang et al.[15].)

The first two RRVs (i.e., $\mathrm{f}_{\mathrm{ct}}$ and $\varepsilon_{\mathrm{ct}}$ ) represent the stress and strain at the transitional point (TP), and the latter two RRVs(i.e., $\mathrm{f}_{\mathrm{cu}}$ and $\left.\varepsilon_{\mathrm{cu}}\right)$ denote the stress and strain at the failure of specimens under tests. In both types of stress-strain curves described in Fig.3, these is an initial stage displaying the ascending branch until the stress reaches the peak which is defined as TP. Afterwards, there would be a descending and non-linear trend until the specimen fails. The difference between the two types of curves in Fig.3 lies in that the ultimate deformation (i.e., $\varepsilon_{\mathrm{cu}}$ ) in FRP-confined specimens is significantly higher. 
More details of IVs related to the characteristics of cylindrical specimens are listed in Table 5.

\section{Table 5.}

Details of IVs related to cylindrical specimens

\begin{tabular}{|c|c|c|c|c|c|c|c|c|c|}
\hline Specimen & $\begin{array}{l}\text { Number of } \\
\text { Specimens }\end{array}$ & ${ }^{\mathrm{a}} \rho_{f r p}$ & $\begin{array}{l}t_{f r p} \\
(\mathrm{~mm})\end{array}$ & $n_{f r k}$ & $\begin{array}{c}\text { Average } f_{\text {co }} \\
(\mathrm{MPa})\end{array}$ & $\begin{array}{c}\text { Average } \\
\text { Ec } \\
\left(\mathrm{N} / \mathrm{mm}^{2}\right)\end{array}$ & $\begin{array}{c}d \\
(\mathrm{~mm})\end{array}$ & $\begin{array}{l}h \\
(\mathrm{~m} \\
\mathrm{m})\end{array}$ & $\begin{array}{l}h / \\
d\end{array}$ \\
\hline $\mathrm{C}_{2} \mathrm{P} \mathrm{S}_{1}$ & 3 & 0.000 & 0 & 0 & 16.9 & 18818.00 & 50 & 100 & 2 \\
\hline $\mathrm{C}_{2} \mathrm{P} \mathrm{S}_{2}$ & 3 & 0.000 & 0 & 0 & 22.1 & 19583.00 & 100 & 200 & 2 \\
\hline С2P0M & 3 & 0.000 & 0 & 0 & 25.2 & 21481.00 & 150 & 300 & 2 \\
\hline $\mathrm{C}_{2} \mathrm{P}_{0} \mathrm{~L}_{1}$ & 3 & 0.000 & 0 & 0 & 24.7 & 20109.00 & 200 & 400 & 2 \\
\hline $\mathrm{C}_{2} \mathrm{P} \mathrm{L}_{2}$ & 3 & 0.000 & 0 & 0 & 23.1 & 19222.00 & 300 & 600 & 2 \\
\hline $\mathrm{C}_{2} \mathrm{P} \mathrm{T}_{1}$ & 3 & 0.000 & 0 & 0 & 24.1 & 21390.00 & 150 & 450 & 3 \\
\hline $\mathrm{C}_{2} \mathrm{POT}_{2}$ & 3 & 0.000 & 0 & 0 & 23.1 & 20730.00 & 150 & 600 & 4 \\
\hline $\mathrm{C} 2 \mathrm{P} 2 \mathrm{~S}_{1}$ & 3 & 0.065 & 1.72 & 2 & 16.9 & 21268.00 & 50 & 100 & 2 \\
\hline $\mathrm{C} 2 \mathrm{P} 4 \mathrm{~S}_{2}$ & 3 & 0.065 & 2.89 & 4 & 22.1 & 22181.00 & 100 & 200 & 2 \\
\hline C2P6M & 3 & 0.065 & 4.25 & 6 & 25.2 & 23306.00 & 150 & 300 & 2 \\
\hline $\mathrm{C}_{2} \mathrm{P}_{1} \mathrm{~L}_{1}$ & 3 & 0.065 & 5.12 & 8 & 24.7 & 18580.00 & 200 & 400 & 2 \\
\hline $\mathrm{C} 2 \mathrm{P} 12 \mathrm{~L}_{2}$ & 3 & 0.065 & 7.06 & 1 & 23.1 & 17822.00 & 300 & 600 & 2 \\
\hline $\mathrm{C} 2 \mathrm{P}_{6} \mathrm{~T}_{1}$ & 3 & 0.065 & 4.25 & 6 & 24.1 & 21469.00 & 150 & 450 & 3 \\
\hline $\mathrm{C} 2 \mathrm{P}_{6} \mathrm{~T}_{2}$ & 3 & 0.065 & 4.25 & 6 & 23.1 & 19212.00 & 150 & 600 & 4 \\
\hline СЗР0M & 3 & 0.000 & 0 & 0 & 33.2 & 21429.00 & 150 & 300 & 2 \\
\hline $\mathrm{C} 3{ }_{2} \mathrm{~S}_{1}$ & 3 & 0.065 & 1.72 & 2 & 33.1 & 22196.00 & 50 & 100 & 2 \\
\hline $\mathrm{C}_{3 \mathrm{P}} 4 \mathrm{~S}_{2}$ & 3 & 0.065 & 2.89 & 4 & 33.1 & 21838.00 & 100 & 200 & 2 \\
\hline С3Р6М & 3 & 0.065 & 4.25 & 6 & 33.2 & 22175.00 & 150 & 300 & 2 \\
\hline $\mathrm{C} \mathrm{P} 8 \mathrm{~L}_{1}$ & 3 & 0.065 & 5.12 & 8 & 33.1 & 21550.00 & 200 & 400 & 2 \\
\hline $\mathrm{C} \mathrm{P} 12 \mathrm{~L}_{2}$ & 3 & 0.065 & 7.06 & 1 & 33.0 & 20233.00 & 300 & 600 & 2 \\
\hline $\mathrm{C}_{3 \mathrm{P} 6 \mathrm{~T}_{1}}$ & 3 & 0.065 & 4.25 & 6 & 33.1 & 22947.00 & 150 & 450 & 3 \\
\hline C3P6T 2 & 3 & 0.065 & 4.25 & 6 & 33.2 & 22398.00 & 150 & 600 & 4 \\
\hline C2F0M & 3 & 0.000 & 0 & 0 & 27.5 & 15728.27 & 150 & 300 & 2 \\
\hline C3F0M & 3 & 0.000 & 0 & 0 & 32.8 & 16038.50 & 150 & 300 & 2 \\
\hline C3F0S & 3 & 0.000 & 0 & 0 & 23.3 & 15415.16 & 75 & 150 & 2 \\
\hline $\mathrm{C}_{3} \mathrm{FOL}_{2}$ & 3 & 0.000 & 0 & 0 & 27.7 & 15476.80 & 300 & 600 & 2 \\
\hline C2F3M & 3 & 0.049 & 1.845 & 3 & 27.5 & 14354.05 & 150 & 300 & 2 \\
\hline C2F6M & 3 & 0.098 & 3.690 & 6 & 27.5 & 14703.76 & 150 & 300 & 2 \\
\hline C2F9M & 3 & 0.147 & 5.535 & 9 & 27.6 & 13664.19 & 150 & 300 & 2 \\
\hline C3F3M & 3 & 0.049 & 1.845 & 3 & 32.8 & 16404.51 & 150 & 300 & 2 \\
\hline C3F6M & 3 & 0.098 & 3.690 & 6 & 32.9 & 15972.29 & 150 & 300 & 2 \\
\hline C3F9M & 3 & 0.147 & 5.535 & 9 & 32.8 & 16043.55 & 150 & 300 & 2 \\
\hline C3F3S & 3 & 0.098 & 1.845 & 3 & 23.3 & 12828.42 & 75 & 150 & 2 \\
\hline $\mathrm{C}_{3 \mathrm{~F}} 12 \mathrm{~L}_{2}$ & 3 & 0.098 & 7.380 & 1 & 27.7 & 15320.86 & 300 & 600 & 2 \\
\hline
\end{tabular}

${ }^{\mathrm{a}}$ : Fiber volume content of the specimens was calculated following the formula provided in Huang et al. [15].

The definitions of IVs listed in Table 5 can be found in Table 4 . For example, $f_{c o}$ is defined as the compressive strength of the unconfined RAC-RCBA cylinder, and 


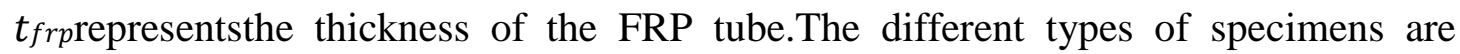
defined with a six-digit term in Table 5. For example, C2P2S1 indicates concrete specimen with the unconfined design strength between 20 and $30 \mathrm{MPa}$, encased in two-layer PFRP and small-sized cylinders. The fourth digit which is a numerical value means the number ofFRP layers. P0 or F0 would mean no layer of FRP (i.e., unconfined specimens). The size of specimens (i.e., S, M, L, and T) may be further divided into sub-categories, withS $\mathrm{S}_{1}$ representing $50 \mathrm{~mm} \times 100 \mathrm{~mm}, \mathrm{~S}_{2}$ denoting $100 \mathrm{~mm}$ $\times 200 \mathrm{~mm}, \quad$ M standingfor $150 \mathrm{~mm} \times 300 \mathrm{~mm}, \mathrm{~L}_{1}$ being $200 \mathrm{~mm} \times 400 \mathrm{~mm}, \quad \mathrm{~L}_{2}$ indicating $300 \mathrm{~mm} \times 600 \mathrm{~mm}, \mathrm{~T}_{1}$ meaning $150 \mathrm{~mm} \times 450 \mathrm{~mm}$, and $\mathrm{T}_{2}$ representing $150 \mathrm{~mm}$ $\times 600 \mathrm{~mm}$.

2.3. Development of non-linear and mixed regression models in predicting the behavior of FRP tube-encased RCA-RCBA

Multiple potential regression models were proposed and tested in their accuracy of predicting the RRVs of RFP-encased concrete specimens. These models were initiated by Jin et al.[32]by linking multiple IVs in various forms (e.g., linear, non-linear, and mixed methods). They started from the conventional linear approach described in Eq.(1).

Model 1: Multivariate linear regression analysis

$$
Y_{i}=\alpha+\sum_{j=1}^{k} \beta_{j} X_{i j}, \quad i=1, \ldots, n
$$

where $\alpha$ and $\beta$ are constants, and $\beta_{j}$ is the constant accompanying the $j$ th IV. The numerical value $j$ ranges from 1 to $k$, which is the total number of IVs ( $k$ equals to 10in this study). The value $i$ ranges from 1 to 4 , corresponding to each RRV defined in Table 3. Besides the linear approach described in Eq.(1), non-linear and mixed models were also proposed by Jin et al.[32]as shown in Eqs. (2)-(5).

Model 2: A non-linear model involving natural logarithms 
$\ln Y_{i}=\alpha+\sum_{j=1}^{k} \beta_{j} X_{i j}, \quad i=1, \ldots, n$

Model 3: A second type of non-linear model involving natural logarithms

$\ln Y_{i}=\alpha+\sum_{j=1}^{k} \beta_{j} \ln X_{i j}, \quad i=1, \ldots, n$

Mixed models from (4) to $(k+3)$

$\frac{X_{i j}}{Y_{i}}=\alpha+\sum_{l=1}^{k} \beta_{l} X_{i l}, \quad i=1, \ldots, n, \quad j=1, \ldots, k$

Mixed models from $(k+4)$ to $(2 k+3)$

$\frac{\ln X_{i j}}{Y_{i}}=\alpha+\sum_{l=1}^{k} \beta_{l} \ln X_{i l}, \quad i=1, \ldots, n, \quad j=1, \ldots, k$

Totally $(2 k+3)$ models were proposed for each RRV. All the models were non-linear except Model 1. However, all these models were in the linear formats by introducing the natural logarithm or mixed approach shown in Eq.(4) and Eq.(5). The statistical software Minitab was adopted to assist the computation of $R^{2}$ and residual standard deviation for each model, which were then used to compare the accuracy among models. Analysis of Variance (ANOVA) were used to test the significance of each model at 5\% level of significance, based on the null hypothesis that the target RRV is not significantly correlated to these IVs using the selected regression model. ANOVA provided the $F$ value and a corresponding $p$ value. A $p$ value lower than 0.05 would reject the null hypothesis and suggest the significant correlation between the IVs and the target RRV using the selected model. Besides ANOVA, coefficient 
analysis was also adopted to measure the individual IVs' effects in the target RRV. A $t$ value and a corresponding $p$ value was computed for each individual IV. The $p$ value lower than 0.05 would indicate the significant effect of this IV in the target RRV. Residual analysis was also conducted to study the distribution and values of residuals, which displayed the differences between the predicted RRV and the experimental values.

\section{Results and Discussion}

The predication performance of the 23 established multivariate models applied in the strength and strain for FRP concrete specimens is evaluated. The best-fit models are identified in predicting these four different types of RRVs (i.e., $\mathrm{Y}_{1}, \mathrm{Y}_{2}, \mathrm{Y}_{3}$, and Y 4 identified in Table 4). Residual analysis is conducted for these best-fit models. The individual factors (i.e., IVs) are analyzed of their effects in each of the four types of RRVs. The internal correlation among the ten IVs are then analyzed before shortlisting the IVs and rerunning the multivariate regression analysis.

\subsection{Comparison among the 23 models}

The multivariate regression analysis for the four different RRVs related to stress and strain illustrated in Fig.3is summarized in Table 6, where the 23 different statistical models are displayed with their prediction performance measured by $R^{2}$ values.

\section{Table 6.}

Multivariate regression results in predicting stress and strain values in the transitional and ultimate states of FRP specimens

\begin{tabular}{|c|c|c|c|c|c|c|c|c|c|}
\hline & & \multicolumn{2}{|c|}{$Y_{1}$-related } & \multicolumn{2}{|c|}{$\mathrm{Y}_{2}$-related } & \multicolumn{2}{|c|}{$\mathrm{Y}_{3}$-related } & \multicolumn{2}{|c|}{$\mathrm{Y}_{4}$-related } \\
\hline & & RRV & $R^{2}$ & RRV & $R^{2}$ & RRV & $R^{2}$ & RRV & $R^{2}$ \\
\hline Linear & 1 & $\mathrm{f}_{\mathrm{ct}}$ & 0.915 & $\varepsilon_{\mathrm{ct}}$ & 0.907 & $\mathrm{f}_{\mathrm{cu}}$ & 0.893 & $\varepsilon_{\mathrm{cu}}$ & 0.862 \\
\hline Non-linear & 2 & $\ln \left(\mathrm{f}_{\mathrm{ct}}\right)$ & 0.920 & $\ln \left(\varepsilon_{\mathrm{ct}}\right)$ & 0.846 & $\ln \left(\mathrm{f}_{\mathrm{cu}}\right)$ & 0.870 & $\ln \left(\varepsilon_{\mathrm{cu}}\right)$ & 0.928 \\
\hline
\end{tabular}




\begin{tabular}{|c|c|c|c|c|c|c|c|c|c|}
\hline \multirow{21}{*}{$\begin{array}{l}\text { Mixed } \\
\text { models }\end{array}$} & 3 & $\ln \left(\mathrm{f}_{\mathrm{ct}}\right)$ & 0.924 & $\ln \left(\varepsilon_{\mathrm{ct}}\right)$ & 0.840 & $\ln \left(\mathrm{f}_{\mathrm{cu}}\right)$ & 0.872 & $\ln \left(\varepsilon_{\mathrm{cu}}\right)$ & 0.922 \\
\hline & 4 & $\rho_{f r p} / \mathrm{f}_{\mathrm{ct}}$ & 0.973 & $\rho f r p / \varepsilon_{\mathrm{ct}}$ & 0.938 & $\rho_{f r p} / \mathrm{f}_{\mathrm{cu}}$ & 0.984 & $\rho_{f r p} / \varepsilon_{\mathrm{cu}}$ & 0.848 \\
\hline & 5 & $t_{f r p} / \mathrm{f}_{\mathrm{ct}}$ & 0.980 & $t_{f r p /} \varepsilon_{\mathrm{ct}}$ & 0.975 & $t_{f r p} / \mathrm{f}_{\mathrm{cu}}$ & 0.990 & $t_{f r p /} \varepsilon_{\mathrm{cu}}$ & 0.905 \\
\hline & 6 & $\mathrm{n}_{f r p /} \mathrm{f}_{\mathrm{ct}}$ & 0.980 & $\mathrm{n}_{f r p /} \varepsilon_{\mathrm{ct}}$ & 0.976 & $\mathrm{n}_{f r p} / \mathrm{f}_{\mathrm{cu}}$ & 0.992 & $\mathrm{n}_{f r p /} \varepsilon_{\mathrm{cu}}$ & 0.923 \\
\hline & 7 & $\mathrm{f}_{f r p /} \mathrm{f}_{\mathrm{ct}}$ & 0.974 & $\mathrm{f}_{f r p /} \varepsilon_{\mathrm{ct}}$ & 0.950 & $\mathrm{f}_{f r p /} \mathrm{f}_{\mathrm{cu}}$ & 0.983 & $\mathrm{f}_{f r p /} \varepsilon_{\mathrm{cu}}$ & 0.894 \\
\hline & 8 & $\varepsilon_{f r p /} \mathrm{f}_{\mathrm{ct}}$ & 0.983 & $\varepsilon_{f r p /} \varepsilon_{\mathrm{ct}}$ & 0.975 & $\varepsilon_{\text {frp } / \mathrm{f}_{\mathrm{cu}}}$ & 0.992 & $\varepsilon_{f r p /} \varepsilon_{\mathrm{cu}}$ & 0.877 \\
\hline & 9 & $\mathrm{E}_{f r p /} \mathrm{f}_{\mathrm{ct}}$ & 0.977 & $\mathrm{E}_{f r p /} \varepsilon_{\mathrm{ct}}$ & 0.939 & $\mathrm{E}_{f r p /} \mathrm{f}_{\mathrm{cu}}$ & 0.983 & $\mathrm{E}_{f r p /} \varepsilon_{\mathrm{cu}}$ & 0.934 \\
\hline & 10 & $f_{c o /} \mathrm{f}_{\mathrm{ct}}$ & 0.808 & $f_{c o /} \varepsilon_{\mathrm{ct}}$ & 0.719 & $f_{c o /} \mathrm{f}_{\mathrm{cu}}$ & 0.864 & $f_{c o /} \varepsilon_{\mathrm{cu}}$ & 0.815 \\
\hline & 11 & $\mathrm{E}_{\mathrm{c} /} / \mathrm{f}_{\mathrm{ct}}$ & 0.893 & $\mathrm{E}_{\mathrm{c} /} \varepsilon_{\mathrm{ct}}$ & 0.786 & $\mathrm{E}_{\mathrm{c} /} \mathrm{f}_{\mathrm{cu}}$ & 0.892 & $\mathrm{E}_{\mathrm{c} /} / \varepsilon_{\mathrm{cu}}$ & 0.787 \\
\hline & 12 & $\mathrm{~d} / \mathrm{f}_{\mathrm{ct}}$ & 0.971 & $\mathrm{~d} / \varepsilon_{\mathrm{ct}}$ & 0.778 & $\mathrm{~d}_{/} \mathrm{f}_{\mathrm{cu}}$ & 0.974 & $\mathrm{~d} / \varepsilon_{\mathrm{cu}}$ & 0.816 \\
\hline & 13 & $\mathrm{~h} / \mathrm{d} / \mathrm{f}_{\mathrm{ct}}$ & 0.958 & $\mathrm{~h} / \mathrm{d} / \varepsilon_{\mathrm{ct}}$ & 0.845 & $\mathrm{~h} / \mathrm{d} / \mathrm{f}_{\mathrm{cu}}$ & 0.942 & $\mathrm{~h} / \mathrm{d} / \varepsilon_{\mathrm{cu}}$ & 0.825 \\
\hline & 14 & $\ln \left(\rho_{f r p}\right) / \mathrm{f}_{\mathrm{ct}}$ & 0.971 & $\ln \left(\rho_{f r p}\right) / \varepsilon_{\mathrm{ct}}$ & 0.838 & $\ln \left(\rho_{f r p}\right) / \mathrm{f}_{\mathrm{cu}}$ & 0.959 & $\ln \left(\rho_{f r p}\right) / \varepsilon_{\mathrm{cu}}$ & 0.866 \\
\hline & 15 & $\ln \left(t_{f r p}\right) / \mathrm{f}_{\mathrm{ct}}$ & 0.978 & $\ln \left(t_{f r p}\right) / \varepsilon_{\mathrm{ct}}$ & 0.886 & $\ln \left(t_{f r p}\right) / \mathrm{f}_{\mathrm{cu}}$ & 0.980 & $\ln \left(t_{f r p}\right) / \varepsilon_{\mathrm{cu}}$ & 0.875 \\
\hline & 16 & $\ln \left(\mathrm{n}_{f r p}\right) / \mathrm{f}_{\mathrm{ct}}$ & 0.978 & $\ln \left(\mathrm{n}_{f r p}\right) / \varepsilon_{\mathrm{ct}}$ & 0.890 & $\ln \left(\mathrm{n}_{f r p}\right) / \mathrm{f}_{\mathrm{cu}}$ & 0.981 & $\ln \left(\mathrm{n}_{f r p}\right) / \varepsilon_{\mathrm{cu}}$ & 0.875 \\
\hline & 17 & $\ln \left(\mathrm{f}_{f r p}\right) / \mathrm{f}_{\mathrm{ct}}$ & 0.977 & $\ln \left(\mathrm{f}_{f r p}\right) / \varepsilon_{\mathrm{ct}}$ & 0.906 & $\ln \left(\mathrm{f}_{f r p}\right) / \mathrm{f}_{\mathrm{cu}}$ & 0.985 & $\ln \left(\mathrm{f}_{f r p}\right) / \varepsilon_{\mathrm{cu}}$ & 0.880 \\
\hline & 18 & $\ln (\varepsilon f r p) / \mathrm{f}_{\mathrm{ct}}$ & 0.975 & $\ln (\varepsilon f r p) / \varepsilon_{\mathrm{ct}}$ & 0.893 & $\ln (\varepsilon f r p) / \mathrm{f}_{\mathrm{cu}}$ & 0.981 & $\ln (\varepsilon f r p) / \varepsilon_{\mathrm{cu}}$ & 0.874 \\
\hline & 19 & $\ln \left(\mathrm{E}_{f r p}\right) / \mathrm{f}_{\mathrm{ct}}$ & 0.977 & $\ln \left(\mathrm{E}_{f r p}\right) / \varepsilon_{\mathrm{ct}}$ & 0.874 & $\ln \left(\mathrm{E}_{f r p}\right) / \mathrm{f}_{\mathrm{cu}}$ & 0.978 & $\ln \left(\mathrm{E}_{f r p}\right) / \varepsilon_{\mathrm{cu}}$ & 0.873 \\
\hline & 20 & $\ln \left(f_{c o}\right) / \mathrm{f}_{\mathrm{ct}}$ & 0.883 & $\ln \left(f_{c o}\right) / \varepsilon_{\mathrm{ct}}$ & 0.736 & $\ln \left(f_{c o}\right) / \mathrm{f}_{\mathrm{cu}}$ & 0.827 & $\ln \left(f_{c o}\right) / \varepsilon_{\mathrm{cu}}$ & 0.853 \\
\hline & 21 & $\ln \left(\mathrm{E}_{\mathrm{c}}\right) / \mathrm{f}_{\mathrm{ct}}$ & 0.913 & $\ln \left(\mathrm{E}_{\mathrm{c}}\right) / \varepsilon_{\mathrm{ct}}$ & 0.761 & $\ln \left(\mathrm{E}_{\mathrm{c}}\right) / \mathrm{f}_{\mathrm{cu}}$ & 0.852 & $\ln \left(\mathrm{E}_{\mathrm{c}}\right) / \varepsilon_{\mathrm{cu}}$ & 0.849 \\
\hline & 22 & $\ln (\mathrm{d}) / \mathrm{f}_{\mathrm{ct}}$ & 0.911 & $\ln (\mathrm{d}) / \varepsilon_{\mathrm{ct}}$ & 0.741 & $\ln (\mathrm{d}) / \mathrm{f}_{\mathrm{cu}}$ & 0.875 & $\ln (\mathrm{d}) / \varepsilon_{\mathrm{cu}}$ & 0.847 \\
\hline & 23 & $\ln (\mathrm{h} / \mathrm{d}) / \mathrm{f}_{\mathrm{ct}}$ & 0.956 & $\ln (\mathrm{h} / \mathrm{d}) / \varepsilon_{\mathrm{ct}}$ & 0.851 & $\ln (\mathrm{h} / \mathrm{d}) / \mathrm{f}_{\mathrm{cu}}$ & 0.947 & $\ln (\mathrm{h} / \mathrm{d}) / \varepsilon_{\mathrm{cu}}$ & 0.836 \\
\hline
\end{tabular}

*Models that achieves the highest $R^{2}$ values are highlighted under each RRV.

According to Table 6, several mixed models outperform the linear regression model, especially Models 5, 6, and 8 which were found superior in predicting all of these four RRVs. The multivariate regression equations of Model 6, which performs superior, are showcased from Equ. (6) to (9) for the four types ofRRVs respectively.

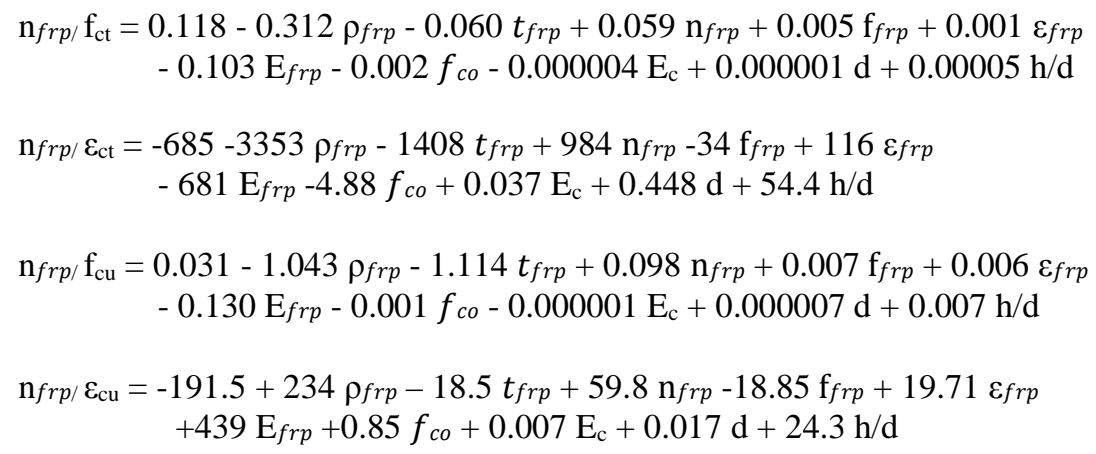

It can be further found from Table 6 that the prediction accuracy of these proposed models could achieve over $97 \%$ for $f_{\mathrm{ct}}, \varepsilon_{\mathrm{ct}}$, and $f_{\mathrm{cu}}$, and the performance of each model for these first three types of RRVsis generally consistent. For example, 
Models 5, 6, and 8 all turned out superior. However, models for $\varepsilon_{\mathrm{cu}}\left(\right.$ i.e., $\mathrm{Y}_{4}$ ) seemed different.The non-linear Model (i.e., Model 2), mixed models in Model 6 and 9 appeared superior than others in predicting $\varepsilon_{\mathrm{cu}}$-related RRVs.

\subsection{Regression analysis using the best-fit models}

These best-fit models following Table 6 are further analyzed based on the comparison between the experimental value and the predicted value calculated from the pre-established multivariate regression model. Fig.4 demonstrates the linear correlation between the experimental and modeled RRV values by using Model 1 and Model 6.

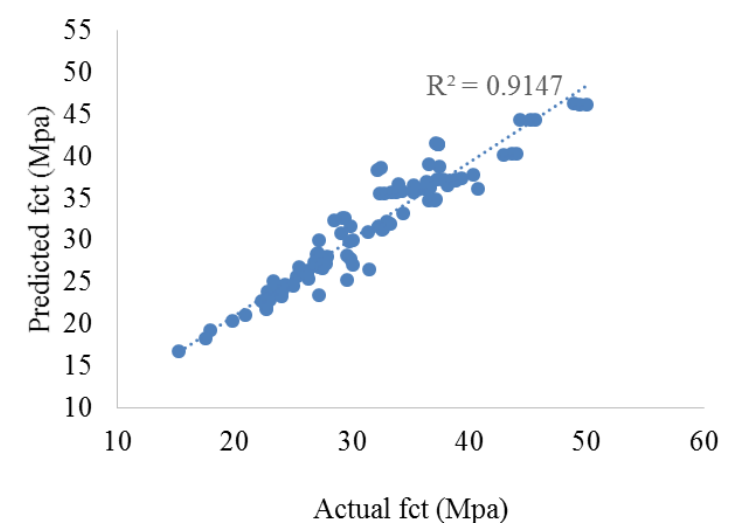

(a) Model 1 to predict $\mathrm{f}_{\mathrm{ct}}$

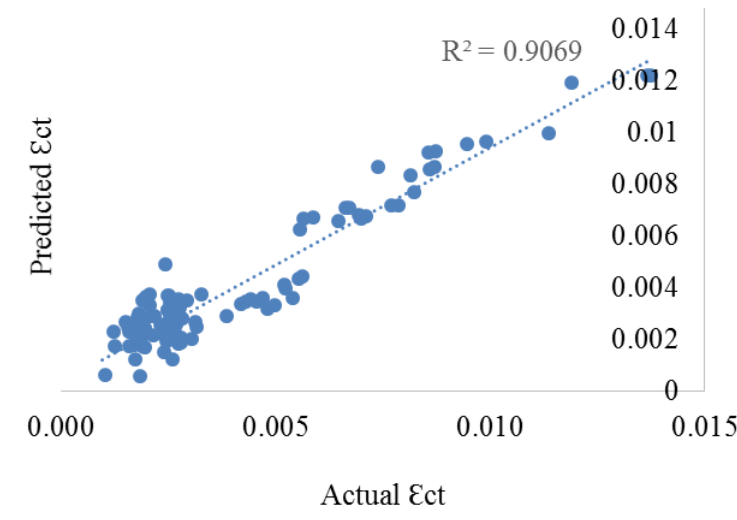

(c) Model 1 to predict $\varepsilon_{\mathrm{ct}}$

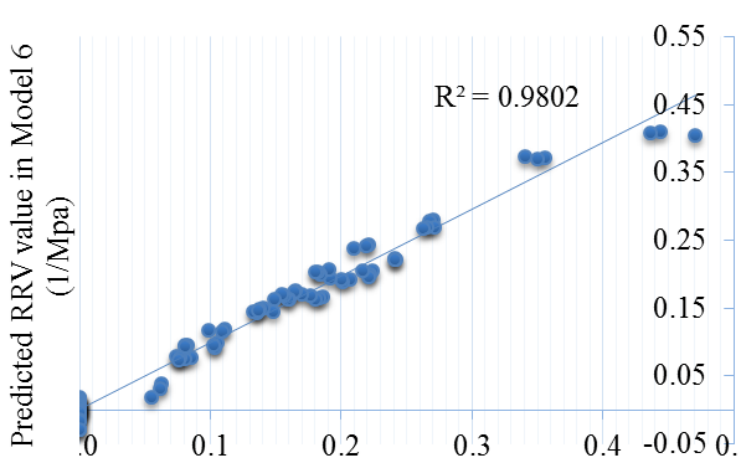

Actual RRV value in Model 6 (1/Mpa)

(b) Model 6 to predict $\mathrm{n}_{f r p /} \mathrm{f}_{\mathrm{ct}}$

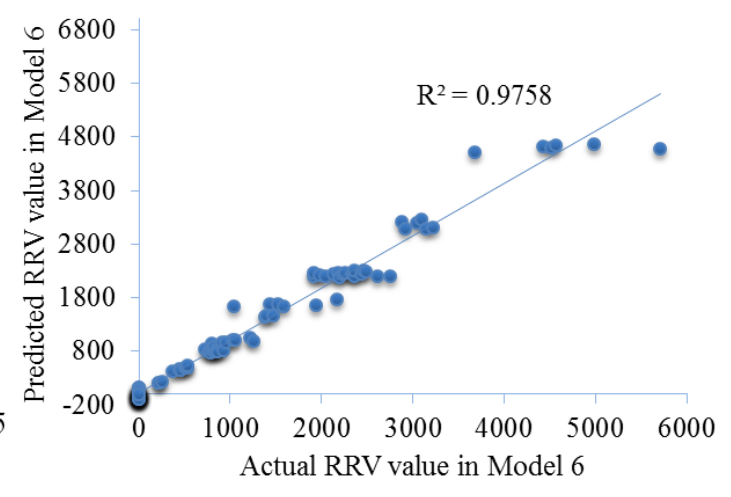

(d) Model 6 to predict $\mathrm{n}_{\text {frp }} / \mathcal{E}_{\mathrm{ct}}$ 


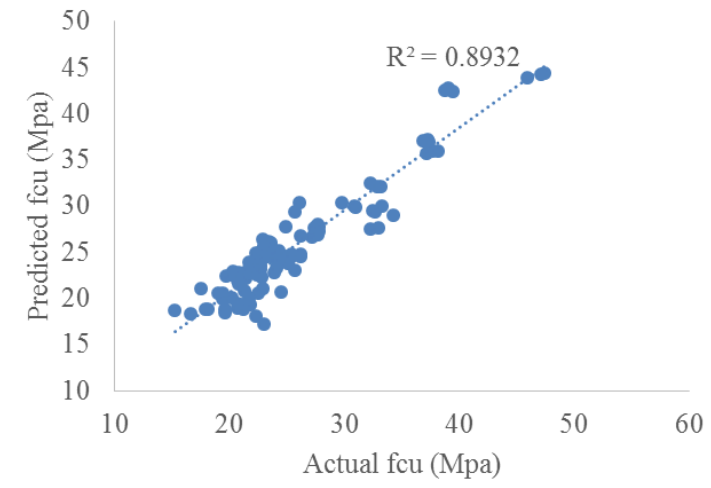

(e) Model 1 to predict $\mathrm{f}_{\text {cu }}$

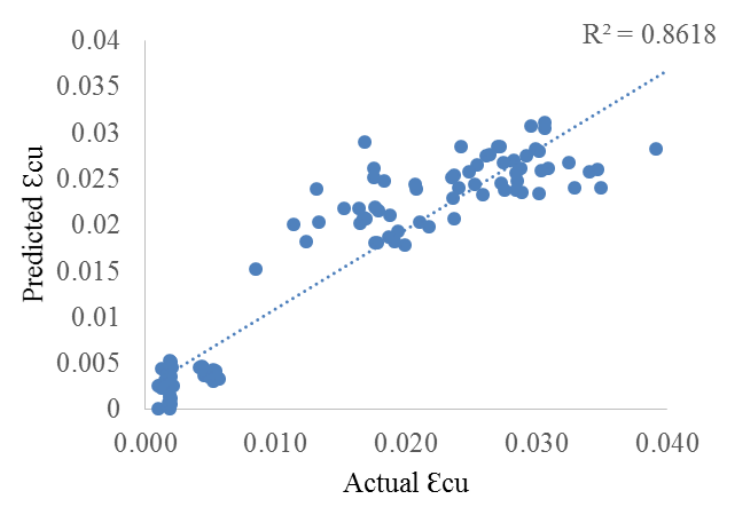

(g) Model 1 to predict $\varepsilon_{\mathrm{cu}}$

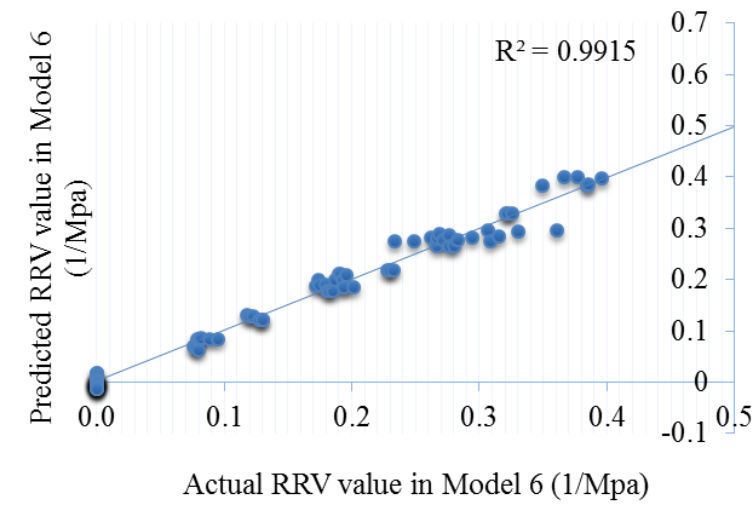

(f) Model 6 to predict $\mathrm{n}_{\text {frp }} \mathrm{f}_{\mathrm{cu}}$

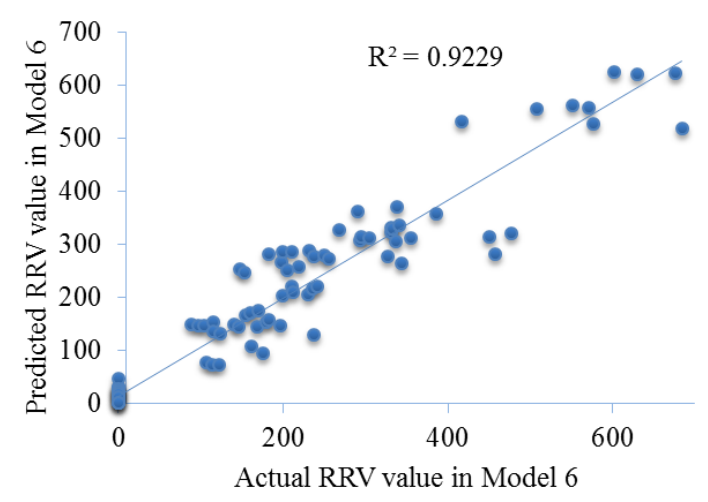

(h) Model 6 to predict $\mathrm{n}_{f r p} / \varepsilon_{\mathrm{cu}}$

Fig. 4. Comparison between the predicted RRV and experimental data using Model 1 and Model 6

The regression equations of Model 1 are presented in Equ. (10) to (13).

$$
\begin{aligned}
\mathrm{f}_{\mathrm{ct}}=1.89+ & 130.4 \rho_{f r p}+4.22 t_{f r p}-2.160 \mathrm{n}_{f r p}-0.901 \mathrm{f}_{f r p}+0.610 \varepsilon_{f r p} \\
& +20.30 \mathrm{E}_{f r p}+0.834 f_{c o}+0.0002 \mathrm{E}_{\mathrm{c}}+0.005 \mathrm{~d}-0.526 \mathrm{~h} / \mathrm{d} \\
\varepsilon_{\mathrm{ct}}=0.011+ & 0.090 \rho_{f r p}-0.002 t_{f r p}+0.001 \mathrm{n}_{f r p}-0.001 \mathrm{f}_{f r p}+0.001 \varepsilon_{f r p} \\
& +0.016 \mathrm{E}_{f r p}+0.0002 f_{c o}-0.000001 \mathrm{E}_{\mathrm{c}}-0.000003 \mathrm{~d}-0.001 \mathrm{~h} / \mathrm{d} \\
\mathrm{f}_{\mathrm{cu}}=21.21 & +273.1 \rho_{f r p}-1.63 t_{f r p}+0.92 \mathrm{n}_{f r p}-1.687 \mathrm{f}_{f r p}+1.010 \varepsilon_{f r p} \\
& +34.51 \mathrm{E}_{f r p}+0.538 f_{c o}-0.0005 \mathrm{E}_{\mathrm{c}}+0.004 \mathrm{~d}-0.752 \mathrm{~h} / \mathrm{d} \\
\varepsilon_{\mathrm{cu}}=0.027+ & 0.066 \rho_{f r p}+0.006 t_{f r p}-0.004 \mathrm{n}_{f r p}+0.001 \mathrm{f}_{r r p}-0.0004 \varepsilon f r p \\
& -0.026 \mathrm{E}_{f r p}-0.00005 f_{c o}-0.000001 \mathrm{E}_{\mathrm{c}}-0.000002 \mathrm{~d}-0.003 \mathrm{~h} / \mathrm{d}
\end{aligned}
$$

Model 1, representing the conventional linear regression approach is compared with one of the best-fit models (i.e., Model 6) in Fig.4. Generally, it is seen that Model 6 outperforms Model 1 for all the four types of RRVs. Similar performance of the other best-fit model (i.e., Model 5) can be found as Model 6 does in Fig.4. Besides the comparison of $R^{2}$ value between Model 1 and Model 6, a further residual analysis 
is conducted. Fig.5 and Fig.6 demonstrate the comparison between Model 1 and Model 6 by using $\mathrm{Y}_{2}$-based RRV as the example.

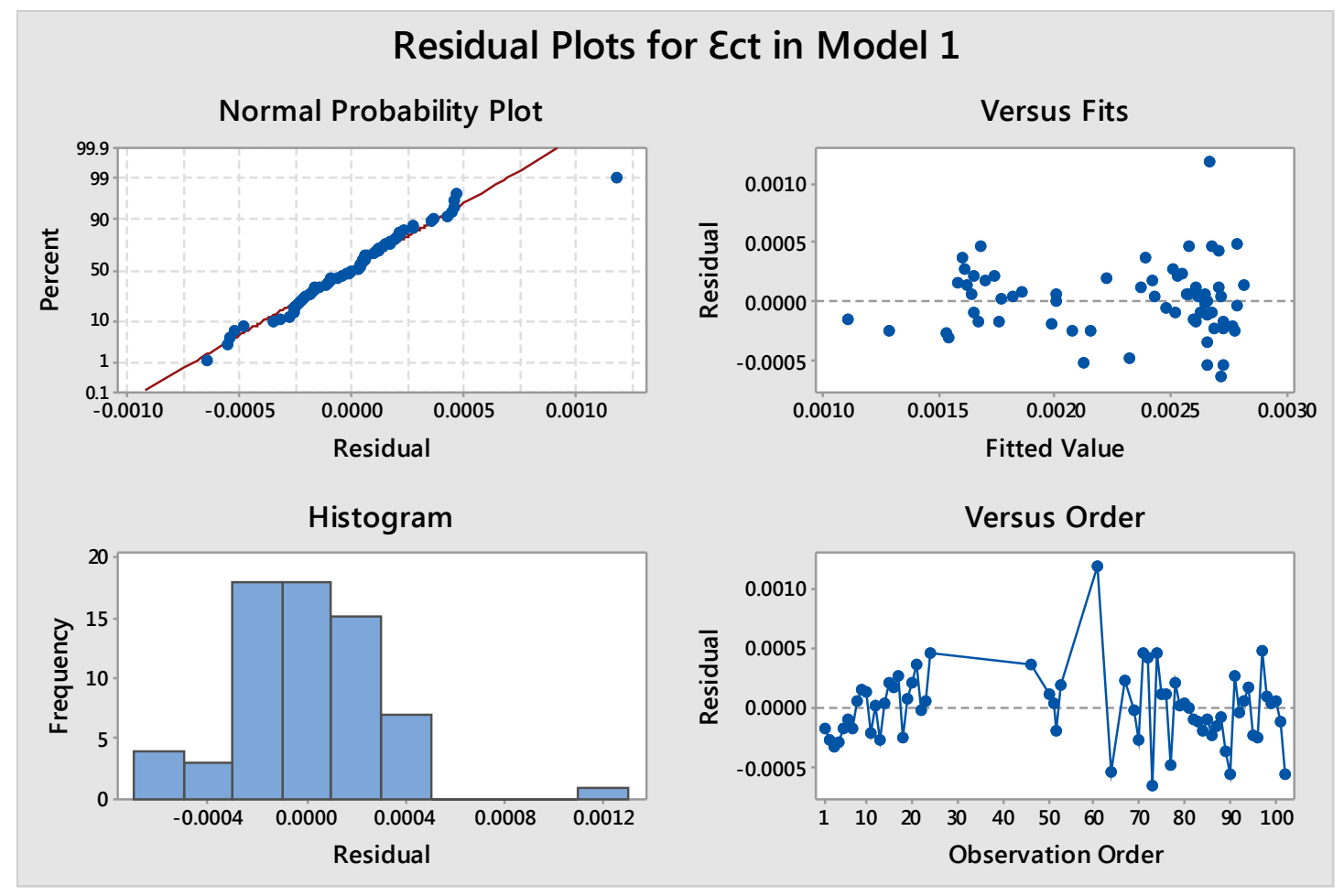

Fig. 5. Residual analysis of Model 1 in predicting $\varepsilon_{\mathrm{ct}}$

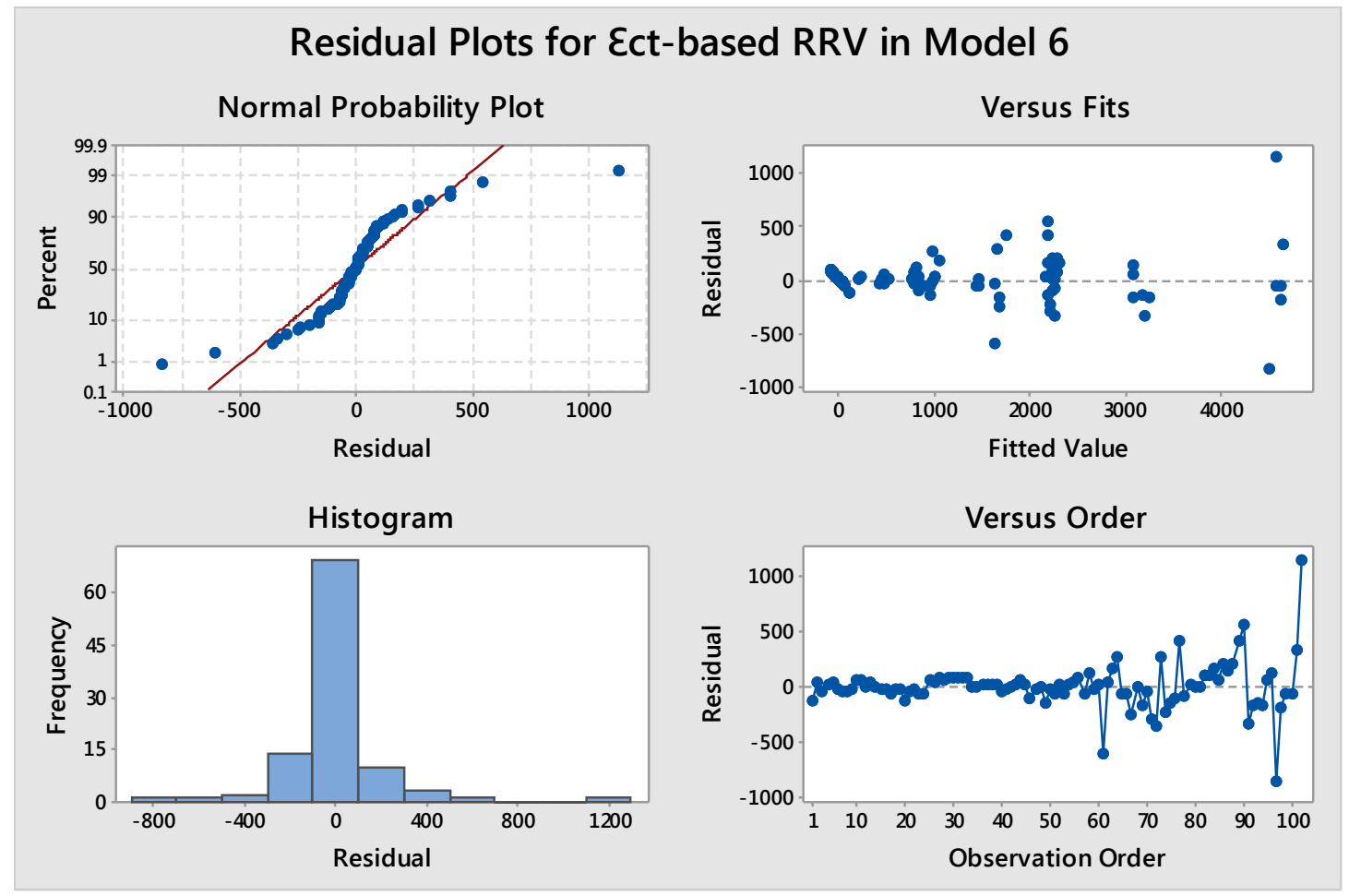

Fig. 6. Residual analysis applying Model 6 in predicting $\varepsilon_{\mathrm{ct}}$-based RRV 
According to Fig.5, the linear regression model, although with its residual values normally distributed, its residual values are not evenly or symmetrically distributed around the neutral line which represents zero residuals. In comparison, Model 6, as the mixed approach, has significantly higher frequency of residuals at 0 . The two residual distribution plots according to Fitted Value and Observation Order further indicated that Model 6 has a superior distribution of residual values, which are more evenly and symmetrically distributed around the neutral line. Similar observations can be found in residual analysis for $\mathrm{Y}_{1}, \mathrm{Y}_{3}$, and $\mathrm{Y}_{4}$.

\subsection{Individual factor analysis}

Multivariate regression analysis can be utilized to analyze the effect of each individual IV in the target RRV. Based on the linear regression model (i.e., Model 1), Table 7 summarizes these individual effects for all the four different types of RRVs (i.e., $f_{\mathrm{ct}}, \varepsilon_{\mathrm{ct},}, f_{\mathrm{cu}}$, and $\left.\varepsilon_{\mathrm{cu}}\right)$.

\section{Table 7.}

Individual factor analysis based on Model 1

\begin{tabular}{|c|c|c|c|c|c|c|c|c|}
\hline \multirow[t]{2}{*}{ IV } & \multicolumn{2}{|c|}{$\mathbf{f}_{\mathrm{ct}}$} & \multicolumn{2}{|c|}{$\varepsilon_{c t}$} & \multicolumn{2}{|c|}{$\mathbf{f}_{\mathrm{cu}}$} & \multicolumn{2}{|r|}{$\varepsilon_{\mathrm{cu}}$} \\
\hline & $\begin{array}{l}t \\
\text { value }\end{array}$ & $\begin{array}{l}p \\
\text { value }\end{array}$ & $\begin{array}{l}t \\
\text { value }\end{array}$ & $\begin{array}{l}p \\
\text { value }\end{array}$ & $\begin{array}{l}t \\
\text { value }\end{array}$ & $\begin{array}{l}p \\
\text { value }\end{array}$ & $\begin{array}{l}t \\
\text { value }\end{array}$ & $\begin{array}{l}p \\
\text { value }\end{array}$ \\
\hline$\rho_{f r p}$ & 5.14 & 0.000 & 8.68 & 0.000 & 10.47 & 0.000 & 1.28 & 0.204 \\
\hline$t_{f r p}$ & 2.30 & 0.024 & -2.74 & 0.007 & -0.87 & 0.388 & 1.67 & 0.098 \\
\hline $\mathrm{n}_{f r p}$ & -2.17 & 0.033 & 2.44 & 0.016 & 0.90 & 0.369 & -2.17 & 0.033 \\
\hline $\mathrm{f}_{f r p}$ & -3.77 & 0.000 & -7.15 & 0.000 & -6.86 & 0.000 & 2.66 & 0.009 \\
\hline$\varepsilon_{f r p}$ & 2.20 & 0.030 & 6.50 & 0.000 & 3.54 & 0.001 & -0.71 & 0.477 \\
\hline $\mathrm{E}_{f r p}$ & 3.87 & 0.000 & 7.41 & 0.000 & 6.40 & 0.000 & -2.44 & 0.016 \\
\hline$f_{c o}$ & 14.41 & 0.000 & 6.52 & 0.000 & 9.03 & 0.000 & -0.46 & 0.646 \\
\hline $\mathrm{E}_{\mathrm{c}}$ & 0.97 & 0.334 & -9.27 & 0.000 & -3.09 & 0.003 & -2.84 & 0.006 \\
\hline d & 0.85 & 0.396 & -1.41 & 0.163 & 0.76 & 0.449 & -0.17 & 0.866 \\
\hline $\mathrm{h} / \mathrm{d}$ & -1.20 & 0.234 & -2.98 & 0.004 & -1.67 & 0.099 & -3.24 & 0.002 \\
\hline
\end{tabular}

Through the multivariate regression-based computation, each IV in Table 7 is assigned with a $t$ value showing the correlational relationship and the significance of 
effect (i.e.,p value). The fiber volume content (i.e., $\mathrm{X}_{1}$ or $\rho_{f r p}$ ) was found with positively significant effects in the strength of RAC specimens at both the transitional and ultimate points. It was also found significantly increasing the strain at the transitional point. However, $\rho_{\text {frp }}$ was found without significant impact on the ultimate strain. Further findings from the individual factor analysis can be generated below:

- The thickness and number of layers (i.e., $\mathrm{X}_{2}$ and $\mathrm{X}_{3}$ ) were found with significant effects in strength and strain in the transitional point. However, the effects would then turn out less significant in the ultimate stage;

- The effects of types of FRP (e.g., PFRP and FFRP) in the RACspecimens' mechanical properties can be measured according to the individual factor analysis of $\mathrm{X}_{4}$ (i.e., $\left.f_{f r p}\right)$ and $\mathrm{X}_{5}$ (i.e, $\varepsilon_{r p}$ ). According to Table 7, the tensile strength of FRP sheets had a significantly negative impact on both the stress and strain of RACspecimens, except the ultimate strain at failure. In contrast, the tensile strain of FRP sheets had a significantly positive impact on RACspecimens’ mechanical properties;

- The original unconfined concrete strength had the highest effect in the same RACspecimen's strength at the transitional point. Although this effect is still significant to the ultimate strength, the effect of the fiber volume content turned out even more significant at the ultimate state;

- Similarly, the unconfined RAC specimens' modulus of elasticity was found with the highest effect in the strain of confined specimen at the transitional point. Nevertheless, this effect was less significant at the ultimate stage;

- The size effect was found with limited effects in these four types of RRVs. Only certain negative effects of $\mathrm{X}_{10}$ (i.e., slenderness ratio) were found in strain-related RRVs. 


\subsection{Internal correlation analysis of IVs based on the best-fit model}

It should be noticed that these ten IVs could be internally correlated to each other. Table 8summarizes the Pearson correlation analysis among these IVs based on the $5 \%$ level of significance.

\section{Table 8.}

Internal correlation analysis among the initial ten IVs

\begin{tabular}{|l|l|l|l|l|l|l|l|l|l|l|l|}
\hline & & $\mathrm{X}_{1}$ & $\mathrm{X}_{2}$ & $\mathrm{X}_{3}$ & $\mathrm{X}_{4}$ & $\mathrm{X}_{5}$ & $\mathrm{X}_{6}$ & $\mathrm{X}_{7}$ & $\mathrm{X}_{8}$ & $\mathrm{X}_{9}$ & $\mathrm{X}_{10}$ \\
\hline $\mathrm{X}_{1}$. & $\mathrm{r}$ & 1.000 & & & & & & & & & \\
$\rho_{f r p}$ & $p$ & 0.000 & & & & & & & & & \\
\hline $\mathrm{X}_{2 .}$ & $\mathrm{r}$ & 0.801 & 1.000 & & & & & & & & \\
$t_{f r p}$ & $p$ & 0.000 & 0.000 & & & & & & & & \\
\hline $\mathrm{X}_{3}$ & $\mathrm{r}$ & 0.786 & 0.994 & 1.000 & & & & & & & \\
$\mathrm{n}_{f r p}$ & $p$ & 0.000 & 0.000 & 0.000 & & & & & & & \\
\hline $\mathrm{X}_{4 .}$ & $\mathrm{r}$ & 0.853 & 0.682 & 0.681 & 1.000 & & & & & & \\
$\mathrm{f}_{f r p}$ & $p$ & 0.000 & 0.000 & 0.000 & 0.000 & & & & & & \\
\hline $\mathrm{X}_{5 .}$ & $\mathrm{r}$ & 0.294 & 0.628 & 0.573 & 0.132 & 1.000 & & & & & \\
$\varepsilon_{f r p}$ & $p$ & 0.003 & 0.000 & 0.000 & 0.187 & 0.000 & & & & & \\
\hline $\mathrm{X}_{6 .}$ & $\mathrm{r}$ & 0.743 & 0.491 & 0.506 & 0.959 & -0.148 & 1.000 & & & & \\
$\mathrm{E}_{f r p}$ & $p$ & 0.000 & 0.000 & 0.000 & 0.000 & 0.138 & 0.000 & & & & \\
\hline $\mathrm{X}_{7 .}$ & $\mathrm{r}$ & 0.278 & 0.294 & 0.289 & 0.290 & 0.147 & 0.239 & 1.000 & & & \\
$f_{c o}$ & $p$ & 0.005 & 0.003 & 0.003 & 0.003 & 0.141 & 0.016 & 0.000 & & & \\
\hline $\mathrm{X}_{8 .}$ & $\mathrm{r}$ & -0.041 & 0.106 & 0.050 & -0.191 & 0.543 & -0.342 & 0.313 & 1.000 & & \\
$\mathrm{E}_{\mathrm{c}}$ & $p$ & 0.685 & 0.291 & 0.620 & 0.055 & 0.000 & 0.000 & 0.001 & 0.000 & & \\
\hline $\mathrm{X}_{9 .}$ & $\mathrm{r}$ & -0.011 & 0.380 & 0.430 & 0.048 & 0.136 & 0.016 & 0.176 & -0.227 & 1.000 & \\
$\mathrm{~d}$ & $p$ & 0.913 & 0.000 & 0.000 & 0.633 & 0.174 & 0.873 & 0.076 & 0.022 & 0.000 & \\
\hline $\mathrm{X}_{10}$. & $\mathrm{r}$ & -0.066 & 0.031 & -0.010 & -0.113 & 0.250 & -0.178 & -0.052 & 0.017 & -0.055 & 1.000 \\
$\mathrm{~h} / \mathrm{d}$ & $p$ & 0.513 & 0.754 & 0.921 & 0.256 & 0.011 & 0.073 & 0.607 & 0.864 & 0.584 & 0.000 \\
\hline
\end{tabular}

$*_{r}$ denotes Pearson correlation, and a $p$ value lower than 0.05 indicates significant correlation between the pair of IVs

Several significant correlations can be found between the pair of IVs. For example, the fiber volume (i.e., $\mathrm{X}_{1}$ )is highly correlated to the the thickness (i.e., $\mathrm{X}_{2}$ ) and number of layers (i.e., $\mathrm{X}_{3}$ ). Therefore, these three IVs can be reduced to keep only one IV. The tensile strength (i.e., $\mathrm{X}_{4}$ ) was found strongly correlated to $\mathrm{X}_{6}$ (i.e., elastic module of FRP sheets), hence one of them could be removed. The IVs related to the tensile strength and strain (i.e., $\mathrm{X}_{4}$ and $\mathrm{X}_{5}$ ) are not correlated to each other. Therefore, both of them should remain in the the next-round shortlisted IVs. Similarly, both $\mathrm{X}_{9}$ and $\mathrm{X}_{10}$ related to the size and slenderness ratio of specimens remain as they are found without significant correlation. By reducing the redundancies of internally-correlated 
IVs, the multivariate regression analyses were redone to the 23 proposed models for the four different types of RRVs. Table 9 showcases the example of Model 5 using Y3-based RRV.

\section{Table 9.}

Regression results from Model 5 for $f_{\text {cu-based RRV }}$

\begin{tabular}{|c|c|c|c|c|c|c|c|c|c|}
\hline \multirow[b]{2}{*}{ RRV } & \multirow[b]{2}{*}{ Predictor } & \multicolumn{3}{|c|}{ Coefficient analysis } & \multirow{2}{*}{$\begin{array}{l}\text { Residual } \\
\text { Standard } \\
\text { Deviation }\end{array}$} & \multirow[b]{2}{*}{$R^{2}$} & \multicolumn{2}{|c|}{ ANOVA } & \multirow{2}{*}{$\begin{array}{l}\text { Durbin- } \\
\text { Watson } \\
\text { value }\end{array}$} \\
\hline & & Coefficient & $t$ value & $\begin{array}{l}p \\
\text { value }\end{array}$ & & & $\begin{array}{l}F \\
\text { value }\end{array}$ & $\begin{array}{l}p \\
\text { value }\end{array}$ & \\
\hline \multirow[t]{11}{*}{$t_{f r p} / \mathrm{f}_{\mathrm{cu}}$} & Constant & 0.022 & 1.46 & 0.147 & 0.011 & 0.990 & 942.5 & 0.000 & 1.812 \\
\hline & $\rho f r p$ & -0.676 & -5.56 & 0.000 & & & & & \\
\hline & $t f r p$ & -0.022 & -2.48 & 0.015 & & & & & \\
\hline & $\mathrm{n} f r p$ & 0.030 & 6.40 & 0.000 & & & & & \\
\hline & $\mathrm{f} f r p$ & 0.004 & 3.86 & 0.000 & & & & & \\
\hline & $\varepsilon f r p$ & 0.004 & 2.76 & 0.007 & & & & & \\
\hline & $\mathrm{E} f r p$ & -0.086 & -3.41 & 0.001 & & & & & \\
\hline & fco & -0.001 & -2.20 & 0.030 & & & & & \\
\hline & Ec & -0.000001 & -1.39 & 0.168 & & & & & \\
\hline & d & 0.000004 & 0.15 & 0.878 & & & & & \\
\hline & $\mathrm{h} / \mathrm{d}$ & 0.005 & 2.23 & 0.028 & & & & & \\
\hline \multirow[t]{8}{*}{$t_{f r p} / \mathrm{f}_{\mathrm{cu}}$} & Constant & -0.021 & -0.62 & 0.537 & 0.027 & 0.939 & 204.9 & 0.000 & 1.369 \\
\hline & $\rho f r p$ & 0.526 & 4.07 & 0.000 & & & & & \\
\hline & $\mathrm{f} f r p$ & 0.0008 & 4.25 & 0.000 & & & & & \\
\hline & $\varepsilon f r p$ & 0.010 & 18.14 & 0.000 & & & & & \\
\hline & $f c o$ & -0.001 & -1.30 & 0.197 & & & & & \\
\hline & Ec & -0.000001 & -0.77 & 0.441 & & & & & \\
\hline & d & 0.0004 & 8.94 & 0.000 & & & & & \\
\hline & $\mathrm{h} / \mathrm{d}$ & -0.0005 & -0.11 & 0.914 & & & & & \\
\hline \multirow[t]{3}{*}{$t_{f r p} / \mathrm{f}_{\mathrm{cu}}$} & Constant & 0.114 & 3.39 & 0.001 & 0.036 & 0.883 & 145.3 & 0.000 & 0.615 \\
\hline & $\rho f r p$ & 0.333 & 1.92 & 0.058 & & & & & \\
\hline & $\mathrm{f} f r p$ & 0.001 & 3.12 & 0.002 & & & & & \\
\hline
\end{tabular}




\begin{tabular}{|c|c|c|c|c|c|c|c|c|c|}
\hline & $\varepsilon f r p$ & 0.012 & 19.00 & 0.000 & & & & & \\
\hline & fco & 0.001 & 1.61 & 0.111 & & & & & \\
\hline & Ec & -0.00001 & -4.35 & 0.000 & & & & & \\
\hline \multirow[t]{3}{*}{$t_{f r p} / \mathrm{f}_{\mathrm{cu}}$} & Constant & -0.164 & -2.77 & 0.007 & 0.079 & 0.438 & 38.59 & 0.000 & 0.241 \\
\hline & $\rho f r p$ & 1.503 & 8.22 & 0.000 & & & & & \\
\hline & Ec & 0.00001 & 3.42 & 0.000 & & & & & \\
\hline
\end{tabular}

${ }^{*} p$ value higher than 0.05 indicating less significant of the target predictor on concrete-strength-based response.

According to Table 9, three more multivariate regression tests were re-performed by reducing the number of IVs for each model, besides the original test with all ten IVs included. The second-round test was conducted by removing the redundant IVs (i.e., $\mathrm{X}_{2}, \mathrm{X}_{3}$, and $\mathrm{X}_{6}$ ) with seven remaining IVs.

The Durbin-Watson statistical test was incorporated in Table 9. It is based on the null hypothesis that residuals from a least square regression are not auto-correlated [43]. The ideal range of Durbin-Watson value is from 1.5 to 2.5[39, 44]. It can be found from Table9 that by removing $\mathrm{X}_{2}, \mathrm{X}_{3}$, and $\mathrm{X}_{6}$, although comparable predication performance could be achieved with the $R^{2}$ value at 0.939 , the Durbin-Watson value would fall out of the ideal range. Furthermore, removing IVs would increase the residual standard deviation and decrease the $F$ value from ANOVA, meaning that the error would be larger and the significance of the same model in predicting the target RRV would be reduced. Further trial of the same model could be performed by removing less-significant IVS, such as size and slenderness related IVs (i.e., $\mathrm{X}_{9}$ and $\mathrm{X}_{10}$ ). The third-round test, according to Table 9, conveys the information that the accuracy, errors of residuals, and Durbin-Watson value are further deteriorated. When the last trail was performed by only keeping $\mathrm{X}_{1}$ and $\mathrm{X}_{8}$, the performance of Model 5 is significantly worse according to the residual standard deviation, $R^{2}$ value, $F$ value, and the Durbin-Watson value. 


\subsection{Discussions of findings from statistical modeling}

By comparing the predication performance of all 23 different models for each of the four types of RRVs (i.e., $f_{\mathrm{ct}}, \varepsilon_{\mathrm{ct}}, f_{\mathrm{cu}}$ and $\varepsilon_{\mathrm{cu}}$, it was discovered that mixed models generally performed better than the traditional linear regression approach, based on the evaluation of accuracy and residual values. By introducing the non-linear and mixed regression approach, the predication accuracy for the strength of FRP-confined RACcylinders could reach over 99\%, and the accuracy for strain could be as high as nearly $98 \%$.

The individual factor analysis generated from multivariate regression analysis quantified the impact of each single factor on the strength and strain of FRP-confined RAC specimens. For example, the compressive strength of unconfined RAC had the most significant effect in the confined strength at the transitional point. However, the effect of the fiber reinforcement content would become more significant than the unconfined RAC strength when specimen reaches the ultimate strength. Compared to three other types of RRV, the ultimate strain of FRP-confined RAC cylinders were less significantly affected by these pre-defined ten IVs.

The multivariate regression analysis provides further in-depth insights continuing from Huang et al.[15] and Yan et al. [17]. For example, when studying the size and slenderness effects in FRP-encased RAC specimens’ mechanical properties, Huang et al. [15]'s initial findings indicated that $f_{\mathrm{ct}}$ decreased with the size or the slenderness ratio, and no significant effects were found in $\varepsilon_{\mathrm{ct}}, f_{\mathrm{cu}}$, and $\varepsilon_{\mathrm{cu}}$. According to the multivariate statistical modeling outcome, $f_{\mathrm{ct}}$ was found with certain negative relationship with the slenderness ratio. However, this relationship was not that significant compared to other individual IVs such as the reinforcement condition of 
RFP and the tensile strength of FRP sheets. More significant impacts of slenderness ratio were found towards the strain than the strength of RFP-refined RACspecimens.

The multivariate regression modeling could be rerun by reducing the redundancy among inter-correlated IVs as well as by removing insignificant IVs. By shortlisting IVs and re-performing the individual factor analysis, highly consistent outcomes were obtained compared to the analysis before shortlisting as shown in Table 7. For example, the slenderness ratio did not have significant effect in $f_{\mathrm{ct}}$ or $f_{\mathrm{cu}}$.Although shortlisting IVs could reduce the internal correlation among IVs, keeping the comprehensive list of IVs was found with superior performance in terms of lowest residual standard deviation, highest $R^{2}$ value, highest $F$ value, and the ideal Durbin-Watson value.

The statistical approach can serve as the prediction tool to estimate concrete strength at a given curing age (e.g., Day 28). The proposed statistical models (e.g., mixed model) can be adopted as an alternative approach complementary to other methods (e.g., genetic programming) in predicting concrete properties. Although other data analytics aproaches such as machine learning or data mining methods [24, 45] could achieve comparatively or even higher accuracy in estimating concrete properties, they have problems of dealing with a large number of IVs [46]. They also rely on software application and require larger and more varied training datasets [45]. Statistical methods developed in this study can handle the drawbacks that the data mining approach faces [32] and achieve a comparable accuracy of estimate. Theyhave the advantages of being less time-consuming in model creation and allowing the analysis of individual concrete mix parameter's effect on concrete properties at different curing ages[32]or at different strength development stages.

\section{Conclusions}


This research applied the newly developed multivariate regression approach in predicting the mechanical properties (i.e., stress and strain) of FRP-confined concrete specimens containing recycled aggregates. The proposed multivariate models were compared of their predication performance based on totally 102 observations for each type of mechanical property. Major conclusions could be reached below:

- it was found consistently among the four different types of mechanical properties (i.e., $f_{\mathrm{ct}}, \varepsilon_{\mathrm{ct}}, f_{\mathrm{cu}}$ and $\left.\varepsilon_{\mathrm{cu}}\right)$ that the same mixed models outperformed the conventional linear approach in terms of higher accuracy and a more ideal distribution of residual values;

- it was indicated that the fiber's properties (i.e., thickness and number of layers) had significant effects on the mechanical properties of FRP-confined concrete in the transitional point, but less on the ultimate strength or strain;

- it was further indicated that the transitional and ultimate behaviors of FRP-confined concrete differed partly due to that fact that the significance of certain independent variables' impacts on concrete properties had changed after passing the transitional point;

- the strength of the originally unconfined concrete was found with the highest degree of impact on the strength of RFP-confined concrete at the transitional point. However, the fiber content was later found with more significance on concrete strength at the ultimate state;

- size and slenderness of specimens were found with less significance in affecting the mechanical properties;

- the multiple independent variables could be shortlisted by removing the inter-correlated items and those found without significant individual effects. However, based on the comprehensive analysis of the modeling performance (i.e., 
accuracy, residual distribution, and significance), it was inferred that removing independent variables could deteriorate the prediction performance.

- the predication of the ultimate strain for FRP-confined concrete turned out less accurate as it was less significantly affected by the pre-defined independent variables.

The scope of current study was limited to statistical validation. For the practical application, an accurate model must be developed for safety and economic design of FRP-confined recycled aggregate concrete as axial structural members. To achieve so, a large database including more experimental results is needed. As the follow-up study, more experimental work can be conducted to investigate the effects of different experimental parameters on the compressive behavior of FRP-confined recycled aggregate concrete. In addition, the established statistical model from this study can be developed for practical prediction of concrete properties.

\section{Acknowledgement}

This study is partially supported by Hunan Provincial Natural Science Foundation of China (No.2015JJ1004). The writers are also grateful for the technical support from staff in Structural Laboratory of Xuchang Jinke Resource Recycling Company in $\mathrm{Xu}$ Chang, China.The authors would also like to acknowledge the Writing Retreat Fund provided by University of Brighton, UK.

\section{References}


[1] M. Henry, Y. Kato, Understanding the regional context of sustainable concrete in Asia: Case studies in Mongolia and Singapore, Resour. Conserv. Recycl. 82 (2014) 86-93.

[2] V.W.Y. Tam, Economic comparison of concrete recycling: A case study approach, Resour. Conserv. Recycl. 52(5) (2008) 821-828.

[3] R. Jin, B. Li, T. Zhou, D. Wanatowski, P. Piroozfar, An empirical study of perceptions towards construction and demolition waste recycling and reuse in China, Resour. Conserv. Recycl. 126 (2017) 86-98.

[4] M. Limbachiya, M. Seddik Meddah, Y. Ouchagour, Performance of portland/silica fume cement concrete produced with recycled concrete aggregate, ACI Mater J 109(1) (2012) 91-100.

[5] N.K. Bui, T. Satomi, H. Takahashi, Mechanical properties of concrete containing $100 \%$ treated coarse recycled concrete aggregate, Constr Build Mater 163 (2018) 496-507.

[6] M. Foroutan, M.M. Hassan, N. Desrosiers, T. Rupnow, Evaluation of the reuse and recycling of drill cuttings in concrete applications, Constr Build Mater 164 (2018) 400-409.

[7] R. Jin, Q. Chen, Investigation of Concrete Recycling in the U.S. Construction Industry, in: W.O. Chong, U. Berardi, K. Parrish, J. Chang (Eds.) International Conference on Sustainable Design, Engineering and Construction, ICSDEC 2015, Elsevier Ltd, 2015, pp. 894-901.

[8] R. Kurda, J. De Brito, J.D. Silvestre, Indirect evaluation of the compressive strength of recycled aggregate concrete with high fly ash ratios, Mag Concr Res 70(4) (2018) 204-216.

[9] A. Gholampour, T. Ozbakkaloglu, Time-dependent and long-term mechanical properties of concretes incorporating different grades of coarse recycled concrete aggregates, Eng. Struct. 157 (2018) 224-234.

[10] C. Gao, L. Huang, L. Yan, G. Ma, L. Xu, Compressive behavior of CFFT with inner steel wire mesh, Composite Structures 133 (2015) 322-330.

[11] P. Yin, L. Huang, L. Yan, D. Zhu, Compressive behavior of concrete confined by CFRP and transverse spiral reinforcement. Part A: experimental study, Materials and Structures/Materiaux et Constructions 49(3) (2016) 1001-1011.

[12] L. Yan, Plain concrete cylinders and beams externally strengthened with natural flax fabric reinforced epoxy composites, Materials and Structures/Materiaux et Constructions 49(6) (2016) 2083-2095.

[13] M. Islam, M.; Choudhury, M. S. I.; Abdulla, M.; and Amin, A. F. M. S. Confinement effect of fiber reinforced polymer wraps in circular and square concrete columns. 4th Annual Paper Meet and 1st Civil Engineering Congress (2011), the Institution of Engineers (IEB), Dhaka, Bangladesh, 359-362. (0000).

[14] J. Xiao, Y. Huang, J. Yang, C. Zhang, Mechanical properties of confined recycled aggregate concrete under axial compression, Constr Build Mater 26(1) (2012) 591-603.

[15] L. Huang, L. Chen, L. Yan, B. Kasal, Y. Jiang, C. Liu, Behavior of polyester FRP tube encased recycled aggregate concrete with recycled clay brick aggregate: Size and slenderness ratio effects, Constr Build Mater 154 (2017) 123-136.

[16] L. Yan, N. Chouw, K. Jayaraman, Effect of column parameters on flax FRP confined coir fibre reinforced concrete, Constr Build Mater 55 (2014) 299-312.

[17] B. Yan, L. Huang, L. Yan, C. Gao, B. Kasal, Behavior of flax FRP tube encased recycled aggregate concrete with clay brick aggregate, Constr Build Mater 136 (2017) 265-276.

[18] Y. Ali, M. Irfan, S. Ahmed, S. Ahmed, Permanent deformation prediction of asphalt concrete mixtures - A synthesis to explore a rational approach, Constr Build Mater 153 (2017) 588-597.

[19] W.Z. Taffese, E. Sistonen, Neural network based hygrothermal prediction for deterioration risk analysis of surface-protected concrete façade element, Constr Build Mater 113 (2016) 34-48.

[20] T.M. Al-zharani, R. Demirboga, W.H. Khushefati, O. Taylan, Measurement and prediction of correction factors for very high core compressive strength by using the adaptive neuro-fuzzy techniques, Constr Build Mater 122 (2016) 320-331.

[21] I. González-Taboada, B. González-Fonteboa, F. Martínez-Abella, J.L. Pérez-Ordóñez, Prediction of the mechanical properties of structural recycled concrete using multivariable regression and genetic programming, Constr Build Mater 106 (2016) 480-499.

[22] M.R.F. Coelho, J.M. Sena-Cruz, L.A.C. Neves, M. Pereira, P. Cortez, T. Miranda, Using data mining algorithms to predict the bond strength of NSM FRP systems in concrete, Constr Build Mater 126 (2016) 484-495.

[23] C. Koo, R. Jin, B. Li, S.H. Cha, D. Wanatowski, Case-based reasoning approach to estimating the strength of sustainable concrete, Comput. Concr. 20(6) (2017) 645-654. 
[24] B.A. Omran, Q. Chen, R. Jin, Comparison of Data Mining Techniques for Predicting Compressive Strength of Environmentally Friendly Concrete, J. Comput. Civ. Eng. 30(6) (2016).

[25] R. Rebouh, B. Boukhatem, M. Ghrici, A. Tagnit-Hamou, A practical hybrid NNGA system for predicting the compressive strength of concrete containing natural pozzolan using an evolutionary structure, Constr Build Mater 149 (2017) 778-789.

[26] H. Erdem, Predicting the moment capacity of RC slabs with insulation materials exposed to fire by ANN, Struct Eng Mech 64(3) (2017) 339-346.

[27] H. Erdem, Predicting residual moment capacity of thermally insulated RC beams exposed to fire using artificial neural networks, Comput. Concr. 19(6) (2017) 711-716.

[28] H. Huang, S.S. Huang, K. Pilakoutas, Modeling for Assessment of Long-Term Behavior of Prestressed Concrete Box-Girder Bridges, J Bridge Eng 23(3) (2018).

[29] T.P. Huynh, C.L. Hwang, A.H. Limongan, The long-term creep and shrinkage behaviors of green concrete designed for bridge girder using a densified mixture design algorithm, Cem Concr Compos 87 (2018) 79-88.

[30] J.F. Liang, M.H. Hu, L.S. Gu, K.X. Xue, Bond behavior between high volume fly ash concrete and steel rebars, Comput. Concr. 19(6) (2017) 625-630.

[31] M. Saridemir, I.B. Topçu, F. Özcan, M.H. Severcan, Prediction of long-term effects of GGBFS on compressive strength of concrete by artificial neural networks and fuzzy logic, Constr Build Mater 23(3) (2009) 1279-1286.

[32] R. Jin, Q. Chen, A.B.O. Soboyejo, Non-linear and mixed regression models in predicting sustainable concrete strength, Constr Build Mater 170 (2018) 142-152.

[33] G. Ma, H. Li, L. Yan, L. Huang, Testing and analysis of basalt FRP-confined damaged concrete cylinders under axial compression loading, Constr Build Mater 169 (2018) 762-774.

[34] P. Zhang, G. Wu, H. Zhu, S.P. Meng, Z.S. Wu, Mechanical performance of the wet-bond interface between FRP plates and cast-in-place concrete, Journal of Composites for Construction 18(6) (2014). [35] L. Huang, C. Zhang, L. Yan, B. Kasal, Flexural behavior of U-shape FRP profile-RC composite beams with inner GFRP tube confinement at concrete compression zone, Composite Structures 184 (2018) 674-687.

[36] D.A. Aderibigbe, T.A.I. Akeju, C.O. Orangun, Optimal water/cement ratios and strength characteristics of some local clay soils stabilized with cement, Materials and Structures 18(2) (1985) 103-108.

[37] I.C. Yeh, Modeling of strength of high-performance concrete using artificial neural networks, Cement and Concrete Research 28(12) (1998) 1797-1808.

[38] N.R. St-Pierre, Invited review. Integrating quantitative findings from multiple studies using mixed model methodology, Journal of Dairy Science 84(4) (2001) 741-755.

[39] J.S. Chou, C.K. Chiu, M. Farfoura, I. Al-Taharwa, Optimizing the prediction accuracy of concrete compressive strength based on a comparison of data-mining techniques, J. Comput. Civ. Eng. 25(3) (2011) 242-253.

[40] R. Nau, Statistical forecasting: notes on regression and time series analysis, Available via <https://people.duke.edu/ rnau/411home.htm>, accessed on 22 Aug 2018. (2018).

[41] ASTM, Standard test method for tensile properties of polymer matrix composite materials, (2008).

[42] ASTM, C39, Standard Test Methods for Compressive Strength of Cylindrical Concrete Specimens., American Society for Testing and Materials (ASTM): West Conshohocken, PA, USA, $2010 . \quad$ (2010).

[43] Ludwig-Maximilians-Universitat Munich, Durbin-Watson significance tables,

Institute for market-based management,,

$<$ http://www.imm.bwl.unimuenchen.de/dateien/3 lehre/market analysis/durbin watson tables.pdf $>$.

[44] S. Chithra, S.R.R.S. Kumar, K. Chinnaraju, F. Alfin Ashmita, A comparative study on the compressive strength prediction models for High Performance Concrete containing nano silica and copper slag using regression analysis and Artificial Neural Networks, Constr Build Mater 114 (2016) 528-535.

[45] U. Atici, Prediction of the strength of mineral admixture concrete using multivariable regression analysis and an artificial neural network, Expert Sys Appl 38(8) (2011) 9609-9618.

[46] W.P.S. Dias, S.P. Pooliyadda, Neural networks for predicting properties of concretes with admixtures, Constr Build Mater 15(7) (2001) 371-379. 
